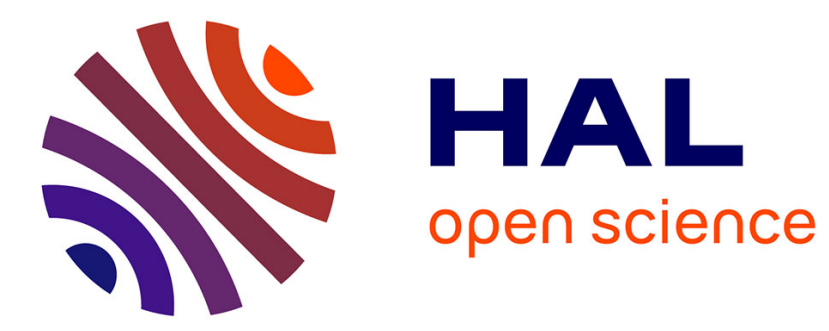

\title{
Gene deletion of Corynespora cassiicola cassiicolin Cas1 suppresses virulence in the rubber tree
}

Sébastien Ribeiro, Dinh Minh Tran, Marine Deon, André Clément-Demange, Dominique Garcia, Mouman Soumahoro, Aurélien Masson, Valérie Pujade-Renaud

\section{To cite this version:}

Sébastien Ribeiro, Dinh Minh Tran, Marine Deon, André Clément-Demange, Dominique Garcia, et al. Gene deletion of Corynespora cassiicola cassiicolin Cas1 suppresses virulence in the rubber tree. Fungal Genetics and Biology, 2019, 129, pp.101-114. 10.1016/j.fgb.2019.05.004 . hal-02624301

\section{HAL Id: hal-02624301 https://hal.inrae.fr/hal-02624301}

Submitted on 26 May 2020

HAL is a multi-disciplinary open access archive for the deposit and dissemination of scientific research documents, whether they are published or not. The documents may come from teaching and research institutions in France or abroad, or from public or private research centers.
L'archive ouverte pluridisciplinaire HAL, est destinée au dépôt et à la diffusion de documents scientifiques de niveau recherche, publiés ou non, émanant des établissements d'enseignement et de recherche français ou étrangers, des laboratoires publics ou privés. 


\section{Accepted Manuscript}

Gene deletion of Corynespora cassiicola cassiicolin Cas1 suppresses virulence in the rubber tree

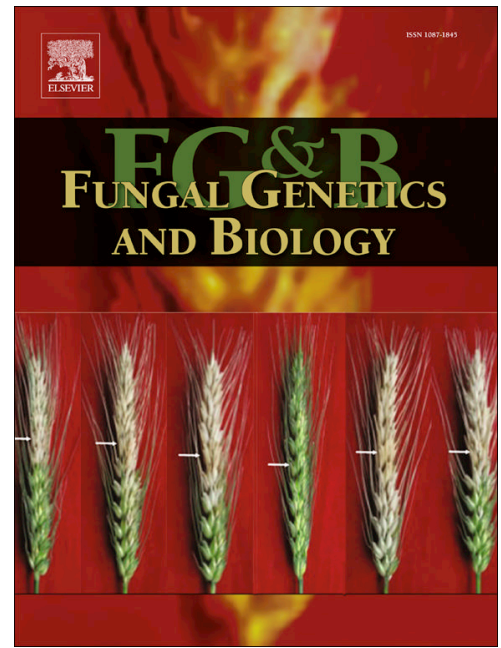

Sébastien Ribeiro, Dinh Minh Tran, Marine Deon, André Clement-Demange, Dominique Garcia, Mouman Soumahoro, Aurélien Masson, Valérie Pujaderenaud

PII: S1087-1845(18)30210-X

DOI: https://doi.org/10.1016/j.fgb.2019.05.004

Reference: YFGBI 3234

To appear in: Fungal Genetics and Biology

Received Date: $\quad 25$ September 2018

Revised Date: $\quad 30$ March 2019

Accepted Date: $\quad 16$ May 2019

Please cite this article as: Ribeiro, S., Minh Tran, D., Deon, M., Clement-Demange, A., Garcia, D., Soumahoro, M., Masson, A., Pujade-renaud, V., Gene deletion of Corynespora cassiicola cassiicolin Cas1 suppresses virulence in the rubber tree, Fungal Genetics and Biology (2019), doi: https://doi.org/10.1016/j.fgb.2019.05.004

This is a PDF file of an unedited manuscript that has been accepted for publication. As a service to our customers we are providing this early version of the manuscript. The manuscript will undergo copyediting, typesetting, and review of the resulting proof before it is published in its final form. Please note that during the production process errors may be discovered which could affect the content, and all legal disclaimers that apply to the journal pertain. 


\section{Gene deletion of Corynespora cassiicola cassiicolin Cas1}

\section{suppresses virulence in the rubber tree}

Sébastien RIBEIRO ${ }^{1,2,3}$, Dinh Minh TRAN ${ }^{2,3,4}$, Marine DEON ${ }^{1}$, André CLEMENT-DEMANGE ${ }^{2,3}$,

Dominique GARCIA ${ }^{2,3}$, Mouman SOUMAHORO ${ }^{5}$, Aurélien MASSON ${ }^{6}$ and Valérie PUJADE-

$\operatorname{RENAUD}^{1,2,3}$

${ }^{1}$ Université Clermont Auvergne, Institut National de la Recherche Agronomique, UMR PIAF,

Clermont-Ferrand, France

${ }^{2}$ CIRAD, UMR AGAP, F-63000 Clermont-Ferrand, France

${ }^{3}$ AGAP, Université Montpellier, CIRAD, Institut National de la Recherche Agronomique, Montpellier SupAgro, Montpellier, France

${ }^{4}$ Rubber Research Institute of Vietnam, Ho Chi Minh City, Vietnam

${ }^{5}$ Société Africaine de Plantations d'Hévéas, 01 BP 1322 Abidjan 01, Côte d'Ivoire

${ }^{6}$ Société des Caoutchoucs de Grand-Béréby, Grand Béréby, Côte d'Ivoire 


\section{Abstract}

Corynespora cassiicola is an ascomycete fungus causing important damages in a wide range of plant hosts, including rubber tree. The small secreted protein cassiicolin is suspected to play a role in the onset of the disease in rubber tree, based on toxicity and gene expression profiles. However, its exact contribution to virulence, compared to other putative effectors, remains unclear.

We created a deletion mutant targeting the cassiicolin gene Casl from the highly aggressive isolate CCP. Wild-type CCP and mutant ccp $\triangle$ cas 1 did not differ in terms of mycelium growth, sporulation, and germination rate in vitro. Cas 1 gene deletion induced a complete loss of virulence on the susceptible clones PB260 and IRCA631, as revealed by inoculation experiments on intact (non-detached) leaves. However, residual symptoms persisted when inoculations were conducted on detached leaves, notably with longer incubation times. Complementation with exogenous cassiicolin restored the mutant capacity to colonize the leaf tissues. We also compared the toxicity of $\mathrm{CCP}$ and ccp $\Delta$ cas 1 culture filtrates, through electrolyte leakage measurements on abraded detached leaves, over a range of clones as well as an F1 population derived from the cross between the clones PB260 (susceptible) and RRIM600 (tolerant). On average, filtrate toxicity was lower but not fully suppressed in ccp $\triangle$ cas 1 compared to $\mathrm{CCP}$, with clone-dependent variations. The two QTL, previously found associated with sensitivity to CPP filtrate or to the purified cassiicolin, were no longer detected with the mutant filtrate, while new QTL were revealed.

Our results demonstrate that: 1) cassiicolin is a necrotrophic effector conferring virulence to the CCP isolate in susceptible rubber clones and 2) other effectors produced by CCP contribute to residual filtrate toxicity and virulence in senescing/wounded tissues. These other effectors may be involved in saprotrophy rather than necrotrophy. 


\section{Key words}

Hevea brasiliensis, Corynespora cassiicola, cassiicolin, deletion mutant, necrotrophy, effector

\section{Abbreviations}

CLF, Corynespora Leaf Fall; QTL, Quantitative Trait Locus; SOGB, Société des caoutchoucs de Grand Béréby; SAPH, Société Africaine de Plantation d'Hévéa; ELM, Electrolyte leakage measurments; PDA, potato dextrose agar; $\mathrm{Cz}$, Czapeck medium; PCR, polymerase chain reaction; CAZymes, carbohydrate-active enzymes; DAMPs, damages-associated patterns; MAMPs, Microbe-associated patterns.

\section{Introduction}

The rubber tree (Hevea brasiliensis) is the world's primary commercial source of natural rubber. In Asia and Africa, H. brasiliensis is affected by the Corynespora leaf fall (CLF) disease, caused by the broad-spectrum ascomycete fungus Corynespora cassiicola (Berk. \& M.A. Curtis) C.T. Wei. C. cassiicola is mostly found associated with plants, either as a necrotrophic pathogen or a non-pathogenic endophyte or saprophyte (Déon et al., 2012b; Dixon et al., 2009) and has also occasionally been isolated from non-plant hosts, including humans (Huang et al., 2010; Yamada et al., 2013; Yan et al., 2016). Since the major epidemic outbreak in Sri Lanka in 1985 (Liyanage et al., 1986), reports of CLF disease have multiplied (Chanruang, 2000; Dung and Hoan, 2000; Jinji et al., 2007; Manju et al., 2001; Manju et al., 2015; Rajalakshmi and Kothandaraman, 1996; Sinulingga and Soepena, 1996; Tan et al., 1992). The pathogen is present throughout the year and affects both mature and immature leaves. Symptoms are brown leaf lesions surrounded by a yellow halo, and occasionally blackening of the veins causing symptomatic "fishbone"-shaped lesions. During severe 
attacks, massive fall of young leaves can occur in susceptible cultivars. The physiological effort devoted to refoliation and the progressive erosion of foliar density result in a decrease in latex production over the years. Given the cost of fungicide applications, farmers often choose to uproot the most susceptible cultivars (clones) and replace them with clones displaying better tolerance. Selection programs aiming to create high yielding rubber clones with better tolerance to leaf diseases are ongoing.

Effector-assisted selection has emerged as a powerful way to select for new resistances against plant pathogens (Vleeshouwers and Oliver, 2014), especially quantitative resistances against necrotrophic fungi (Oliver et al., 2014). This strategy requires previous identification of the effectors controlling the outcome of the interaction with the host. In the rubber tree/C. cassiicola pathosystem, early work identified cassiicolin as a potential CLF-associated effector. Cassiicolin is a phytotoxic cysteine-rich small secreted protein (SSP), counting only 27 amino acids (Breton et al., 2000; de Lamotte et al., 2007). This toxin was purified from the culture filtrate of $\mathrm{CCP}$, a highly virulent strain isolated from diseased rubber tree leaves from the Philippines (Barthe et al., 2007; Breton et al., 2000; de Lamotte et al., 2007). The purified toxin was shown to reproduce the disease symptoms with the same response profile as CCP conidia, over a range of rubber clones of variable sensitivity and a collection of different plant species (Barthe et al., 2007; Breton et al., 2000). Moreover, adding anti-cassiicolin antibodies into a suspension of CCP conidia before inoculation onto the leaves of a susceptible clone (PB260) caused a significant reduction in severity of symptoms compared to inoculated antibody-free controls (Breton et al., 2000). Cassiicolin toxicity is host-specialized (Barthe et al., 2007) and clone-dependent (Déon et al., 2012a), which suggests that cassiicolin interacts, directly or indirectly, with specific plant sensitivity factors. Recently, we have identified two QTL associated with the sensitivity to both the purified cassiicolin and CCP culture filtrate, 
from a biparental F1 progeny (Tran et al., 2016), suggesting that cassiicolin could be the main effector of CCP filtrate toxicity.

The cassiicolin-encoding gene (EF667973.1) was found transiently up-regulated after spore inoculation of rubber tree leaves with $\mathrm{CCP}$, just before the onset of the first symptoms in the susceptible clone, suggesting a role in the early phases of infection (Déon et al., 2012a). However, interaction with the plant is not strictly required for cassiicolin synthesis and secretion by CCP, as the toxin can be produced in vitro, in synthetic culture medium. Virulence was found to be correlated to the cassiicolin gene expression level in two strains producing strictly identical cassiicolin proteins (Déon et al., 2012a).

Studies on the genetic diversity of Corynespora cassiicola strains from various hosts and geographical origins have established a phylogeny based on the assembly of four concatenated loci: ITS, ga4, caa5, and act1 (Déon et al., 2014; Dixon et al., 2009). We found eight major clades, named by letters (from A to $\mathrm{H}$ ), among a collection of 70 strains. As revealed by PCR screening (Déon et al., 2014), 47\% of these strains carried at least one cassiicolin gene, with the existence of six distinct protein isoforms (Cas1 to Cas6). A seventh isoform was recently identified (Lopez et al., 2018). We thus classified the strains into eight toxin classes (Cas0, Cas1, Cas2, Cas3, Cas4, Cas5, Cas2+6 and Cas2+7), with Cas0 corresponding to strains for which no cassiicolin gene was detected. C. cassiicola strains belonging to the toxin class Cas1 appeared to be the most aggressive on two tested rubber clones (Déon et al., 2014).

We recently described all putative effectors in silico from the genome of the CCP reference strain (Lopez et al., 2018). Transcriptomic analysis identified 353 genes differentially expressed during the compatible interaction of CCP with the susceptible rubber clone PB260, among which 92 putative effectors, including cassiicolin. 
Although a body of evidences suggested that Cas 1 is an important effector of CCP virulence in rubber tree, its exact contribution, relatively to other putative effectors, remained unclear. Gene manipulation is a powerful method that helped characterizing several fungal effectors in various pathosystems. In Stagonospora nodurum for example, gene disruption of the SnTox1 or SnTox3 effectors in virulent isolates resulted in the suppression of the disease on wheat lines carrying the matching Snn1 and Snn3 susceptibility loci (Liu et al., 2009; Liu et al., 2012). In C. cassiicola, homologous recombination was recently used for the functional characterization of the CCK1 MAP kinase (Liu et al., 2017). This demonstrated that CCK1 is a versatile regulator of many physiological aspects such as mycelial growth and differentiation, pigmentation, conidiation or production of secreted hydrolytic enzymes, thus indirectly influencing pathogenicity on the rubber tree. Here, we present the functional analysis of cassiicolin through gene deletion of the Cas 1 gene from the virulent $C$. cassiicola CCP strain. We compared the mutant and wild type strains in terms of physiology and virulence, in interaction with several rubber clones of variable susceptibility, through controlled inoculations and toxicity tests followed by QTL analysis.

\section{Material and methods}

\subsection{Plant material}

The rubber clones (grafted from elite cultivars) used in this study were previously described (Tran et al., 2016). Clonal identities were checked using a set of eight microsatellite markers. Eight rubber clones (GT1, IRCA18, IRC41, IRCA631, PB217, PB260, RRIC100 and RRIM600), chosen for their contrasted sensitivity to CLF in african plantations, were used to evaluate the virulence of the deletion mutant compared to the wild-type strain through inoculation tests. They were cultivated in a greenhouse in Clermont-Ferrand (France) at 26- 
$28^{\circ} \mathrm{C}$ under controlled relative humidity (60-80\%). Eighteen rubber clones (CD1174, FDR4575, FDR5240, FDR5665, FDR5788, GT1, IRCA19, IRCA41, IRCA303, MDX607, MDX624, PB217, PB254, PB260, RRIC100, RRIM600, RRIM901 and RRIM926) from the SOGB (Société des caoutchoucs de Grand Béréby) or SAPH-Toupah (Société Africaine de Plantation d'Hévéa, Toupah) plantations in the Ivory Coast were used to characterize fungal toxicity profiles using the ELM-based test (see below). Progenies from the bi-parental F1 family PB260 x RRIM600 were planted in two populations at SOGB (Pop1, 191 genotypes) and SAPH-Toupah (Pop2, 152 genotypes). They were also phenotyped using the ELM-based test to identify QTL associated with sensitivity to the fungal exudates (see below).

\subsection{Fungal material}

Eighteen C. cassiicola isolates from rubber tree were used in this study (Table 1). CCP is a highly virulent strain used as reference genome for the C. cassiicola species (Pujade-Renaud et al., 2014). Strain typology (genetic group/toxin class) was determined as previously described (Déon et al., 2014). All strains were single-conidium-purified and cultivated at $25^{\circ} \mathrm{C}$ in the dark on potato dextrose agar (PDA) medium (DIFC0, Detroit, MI, USA) supplemented with lactic acid (0.02\%), and stored as mycelium plugs in $20 \%$ glycerol, at $80^{\circ} \mathrm{C}$.

For inoculation experiments, conidia suspensions were prepared from 9-day-old mycelium cultures, grown for 7 days in the dark and two more days under alternate light (12-hour photoperiod) at $26^{\circ} \mathrm{C}$. Conidia were collected in $5 \mathrm{ml}$ sterile water and filtered through a 100 $\mu \mathrm{m}$ pore-size cell strainer (Biologix Group Ltd, Jinan, China), to remove mycelium. Conidia were counted four times, with a hemocytometer, and diluted with water, to reach a concentration of $5,10,50$ or 100 conidia/ $\mu 1$ (depending on the experiment). 
For toxicity tests, culture filtrates were prepared as described previously (Tran et al., 2016) from 21-day-old cultures in Czapeck medium (six mycelium plugs in $100 \mathrm{ml}, 25 / 26^{\circ} \mathrm{C}$, 12 -h photoperiod), with final sterilization through $0.20 \mu \mathrm{m}$ disposable filters.

\subsection{Construction of the Cas 1 gene replacement cassette}

The Cas 1 gene replacement cassette was generated using the double-joint PCR procedure described previously (Guillemette et al., 2011; Yu et al., 2004). It is composed of a selectable hygromycin resistance gene ( $h p h$ gene under the control of the $\operatorname{trpC}$ fungal promoter, from plasmid pCB1636 (Sweigard et al., 1995)) framed by the 5' and 3' UTR sequences of the Cas1 gene from the CCP isolate (Fig. 1). The primers used for cassette construction are listed in Table 2. The three elements of the cassette (Fig. 1A) were amplified using Phire ${ }^{\circ}$ Hot Start II DNA Polymerase (Thermo Scientific, Waltham, MA, USA). After purification with a QIAquick PCR Purification Kit (Qiagen, Hilden, Germany), the three amplicons (Cas1 5'UTR, hph gene and Casl 3'UTR) were mixed in a 1:3:1 molar ratio and assembled by PCR (Fig. 1B) using Advantage 2 Polymerase (Clontech, Palo Alto, CA, USA). The final construct was cloned into a TOPO vector (Invitrogen, Carlsbad, CA, USA) and checked by sequencing using primers P7, P8, PTrpC-F1, HygR-F3 and HygR-R1 (Table 2). The cloned cassette was re-amplified using Phire ${ }^{\circledR}$ Hot Start II DNA Polymerase with the nested primer pair P7 and P8 (Fig. 1C), then purified (QIAquick), concentrated by ethanol precipitation to $1 \mu \mathrm{g} / \mu \mathrm{l}$, and stored at $-20^{\circ} \mathrm{C}$ until use.

\subsection{Transformation of $C$. cassiicola protoplasts}

C. cassiicola protoplasts were prepared and transformed using procedures adapted from previous studies (Akamatsu et al., 1997). A conidia suspension from the CCP strain was prepared as described above and diluted to a final concentration of approximately 100 conidia/ $\mu 1$ in $200 \mathrm{ml}$ of potato dextrose broth (PDB, Sigma-Aldrich, St. Louis, MO, USA). 
After $17 \mathrm{~h}$ at $26^{\circ} \mathrm{C}$ with shaking at $175 \mathrm{rpm}$ in the dark, the fungal culture was divided into four $50 \mathrm{ml}$ batches and harvested by centrifugation, at $5,000 \mathrm{~g}$ for $10 \mathrm{~min}$ at room temperature. The pellets were washed twice with $0.7 \mathrm{M} \mathrm{NaCl}$ and digested in $25 \mathrm{ml}$ of enzymatic solution $(0.7 \mathrm{M} \mathrm{NaCl}, 10 \mathrm{mg} / \mathrm{ml} \mathrm{Kitalase}$ and $20 \mathrm{mg} / \mathrm{ml}$ Driselase $)$, at $32^{\circ} \mathrm{C}$ for $3 \mathrm{~h}$, with manual shaking every $30 \mathrm{~min}$. The generated protoplasts were filtered through a $100 \mu \mathrm{m}$ pore-size cell strainer (Biologix), then collected by centrifugation at 4,000 $g$ for $5 \mathrm{~min}$, at room temperature. The pellets were washed with $10 \mathrm{ml}$ of $0.7 \mathrm{M} \mathrm{NaCl}$ and twice with $10 \mathrm{ml}$ of STC buffer (1.2 M Sorbitol, $10 \mathrm{mM}$ Tris- $\mathrm{HCl} \mathrm{pH} 7.5$ and $50 \mathrm{mM} \mathrm{CaCl}_{2}$ ). Each protoplast pellet was resuspended in $500 \mu \mathrm{l}$ of STC buffer, adjusted to a concentration of $10^{7}-10^{8}$ protoplasts $/ \mathrm{ml}$, and divided into $100 \mu \mathrm{l}$ aliquots into $12-15 \mathrm{ml}$ round-bottom tubes. DNA aliquots of the Cas1 gene replacement cassette were added to the protoplasts (10 $\mu \mathrm{g}$ per tube) in order to replace the native Cas 1 gene by the $h p h$ gene, by homologous recombination (Fig. 1D). The tubes were gently mixed by hand-rolling and incubated on ice for $20 \mathrm{~min}$. PEG solution (60\% w/v polyethylene glycol MW 3350-4000, $10 \mathrm{mM}$ Tris- $\mathrm{HCl} \mathrm{pH} 7.5$ and $50 \mathrm{mM}$ $\mathrm{CaCl}_{2}$ ) was added, drop by drop, in three batches (200, 200 and $800 \mu 1$, successively). Tubes were warmed and gently mixed by hand-rolling before and after each PEG addition, then incubated on ice for $5 \mathrm{~min}$ until the next addition. Then, the mixture was diluted with $1 \mathrm{ml}$ of STC buffer. Finally, $150 \mu \mathrm{l}$ of protoplasts were sprayed on a Petri dish containing $20 \mathrm{ml}$ of still soft regeneration medium ( $1 \mathrm{M}$ sucrose, $0.1 \%$ yeast extract, $0.1 \%$ casein hydrolysate, $1.6 \%$ agar). After $24 \mathrm{~h}$ incubation at $26^{\circ} \mathrm{C}$, the plate was covered by $10 \mathrm{ml}$ of water-agar $(1 \%)$ supplemented with $10 \mu \mathrm{g} / \mathrm{ml}$ hygromycin B and incubated for 5 days at $32^{\circ} \mathrm{C}$. As mycelium could grow massively though the selective layer, the selection was increased by successively adding two layers of PDA supplemented with $40 \mu \mathrm{g} / \mathrm{ml}$ then $80 \mu \mathrm{g} / \mathrm{ml}$ hygromycin $\mathrm{B}$. The resistant mycelial colonies were transferred onto fresh PDA plates containing 20, 40 and 60 $\mu \mathrm{g} / \mathrm{ml}$ successively of hygromycin B to confirm resistance. Transformants growing at the 
highest hygromycin concentration $(60 \mu \mathrm{g} / \mathrm{ml})$ were purified by single-conidium isolation. For further use, they were grown on PDA with $60 \mu \mathrm{g} / \mathrm{ml}$ hygromycin.

\subsection{Verification of Cas 1 gene deletion}

Mycelium was collected from 7-day-old cultures of the hygromycin-resistant transformants or CCP wild-type controls. Genomic DNA was extracted following the MATAB protocol (Risterucci et al., 2000). PCR runs were performed from $100 \mathrm{ng}$ of DNA with the Phire® Hot Start DNA Polymerase, according to the supplier's instructions. Several primers were used for PCR reactions or for sequencing (Table 2): M13F, M13R, HygR-F3, HygR-R1 and PTrpC-F1 amplify the $h p h$ gene; P1/P4, P7/P8 and P9/P12 primer pairs amplify the flanking regions of the Casl gene or hph gene; P11 and P10 were used as internal primer for the Cas 1 gene. Amplification was conducted for 35 cycles of $5 \mathrm{sec}$ at $98^{\circ} \mathrm{C}, 5 \mathrm{sec}$ at $60^{\circ} \mathrm{C}, 1 \mathrm{~min}$ at $72^{\circ} \mathrm{C}$. PCR products from P9/P12 were sequenced using all the primers in Table 2 (except P2 and P3) by GATC-Biotech, and aligned using Geneious Pro v10.2.3.

\subsection{Cas 1 gene expression by real-time quantitative PCR}

Cas 1 gene expression was investigated in germinated conidia of the wild-type CCP and five Cas1-deleted transformants. Conidia suspensions were prepared as described above and germinated in malt extract broth (MEB, Sigma-Aldrich, St. Louis, MO, USA), under continuous shaking $(150 \mathrm{rpm})$, for $24 \mathrm{~h}$. The cultures were centrifuged at $8,000 \mathrm{~g}$ for 30 minutes at room temperature and the pellets were immediately frozen and ground in liquid nitrogen. Total RNA was extracted by vortexing (30 sec at full speed) in $900 \mu \mathrm{l}$ of CTAB extraction buffer (Chang et al., 1993) supplemented with $0.2 \mathrm{~g}$ sterile glass beads (425-600 $\mu \mathrm{m}$, acid-washed, Sigma-Aldrich, St. Louis, MO, USA). Samples were treated with RNasefree RQ1 DNase (Promega, Madison, WI, USA). Total RNA (1 $\mu \mathrm{g})$ was reverse-transcribed using oligo-dT and SuperScript III (Invitrogen, Carlsbad, CA, USA) following the 
manufacturer's instructions. Real-time PCR amplification was performed in a StepOne thermocycler (Applied Biosystems, Foster City, CA, USA) using $2 \mu 1$ of 40-fold-diluted firststrand cDNA as template, Takyon ${ }^{\mathrm{TM}}$ Rox SYBR® MasterMix dTTP Blue (Eurogentec, Liège, Belgium) and primers listed in Table 2. The thermal profile used was: $95^{\circ} \mathrm{C}$ for 3 min, 40 cycles of denaturation at $95^{\circ} \mathrm{C}$ for $3 \mathrm{sec}$ and $30 \mathrm{sec}$ of annealing/extending at $60^{\circ} \mathrm{C}$. Amplicon specificity was checked by melting curve analysis $\left(95^{\circ} \mathrm{C}\right.$ for $15 \mathrm{sec}, 60^{\circ} \mathrm{C}$ for 1 min and an increase of $0.5^{\circ} \mathrm{C}$ with a hold of $15 \mathrm{sec}$ to reach $95^{\circ} \mathrm{C}$ ) and agarose gel electrophoresis. All reactions were run in triplicate. Ct values were determined by the StepOne software v2.3 with default parameters. The Casl gene was amplified using the primer pair Cc-qCas1-F1/R1 (Table 2). For normalization, three C. cassiicola reference genes (elongation factor EF1 $\alpha$, Actin, and $\beta$-tubulin BTUB) were amplified with primer pairs Cc-qEF1a-F1/R1, Cc-qActinF1/R1 and Cc-Btub-F1/R1 respectively (Table 2). For each sample, the Excel-based tool BestKeeper (Pfaffl et al., 2004) was used to calculate a Bestkeeper index, which is the geometric mean of the $\mathrm{Ct}$ values obtained for the three reference genes. The deviation from the mean of all BestKeeper indexes was subtracted from the $\mathrm{Ct}$ value obtained with the Caslspecific primers. The transcript accumulation was calculated according to Lopez et al (Lopez et al., 2012). In brief, a linear regression line was created after assigning an arbitrary score of 0 and 100 corresponding to the highest (40) and smallest (20) normalized Cas 1 gene $\mathrm{Ct}$ values, respectively. Transcript accumulations of unknown samples were then determined according to the position of their normalized Cas 1 gene $\mathrm{Ct}$ values on the line.

\subsection{In vitro analysis of sporulation and germination rates}

Mycelium plugs (5 mm diameter) of either the wild-type strain CCP or the conform Cas1deletion mutant ccp $\triangle$ cas 1 were transferred onto the corresponding culture medium (PDA with or without $60 \mu \mathrm{g} / \mathrm{ml}$ hygromycin). Four plates for each condition were incubated in the dark at $26^{\circ} \mathrm{C}$. Mycelium diameter was measured daily for one week in order to compare strain growth 
(mm/day). The same plates were used to prepare the conidia suspensions as previously described. Conidiation, expressed in conidia/ $\mu$, was calculated as the average of the four counts. The conidia suspensions were finally diluted to 10 conidia/ $\mu$ l in sterile water and immediately plated on PDA (10 $\mu$ l per plate). Percentage of germination was recorded after 24 hours of incubation in the dark at $26^{\circ} \mathrm{C}$.

\subsection{Virulence analysis on rubber tree leaves}

Inoculation tests were performed with the wild-type and deleted CCP strains on detached and non-detached rubber tree leaves from greenhouse plants. Conidia suspensions were prepared as described above.

\section{Test on detached leaves:}

Leaves collected at developmental stage C (Hallé and Martin, 1968) were placed on wet paper in $245 \times 245 \mathrm{~mm} \mathrm{Nunc}{ }^{\mathrm{TM}}$ bioassay dishes (Fisher Scientific, Hampton, NH, USA) and inoculated as previously described (Déon et al., 2012a; Déon et al., 2014; Tran et al., 2016) except entirely in the dark. For each clone, five leaflets were inoculated with 6 drops $(20 \mu 1)$ of conidia suspension, on the abaxial surface. In a first experiment, eight rubber clones (GT1, IRCA18, IRC41, IRCA631, PB217, PB260, RRIC100 and RRIM600) were inoculated with a conidia suspension at 5 conidia/ $\mu$ l. In a second experiment, conidia were applied at higher concentration (50 conidia/ $/ \mu \mathrm{l})$ on the tolerant clone GT1 clone and the susceptible clones IRCA631 and PB217, under identical conditions. In a third experiment, the same three clones were inoculated at 5 conidia/ $\mu 1$ after gentle abrasion of the leaf epidermis at the inoculation spots. Negative controls were inoculated with water. At least four biological replicates were performed for each condition. Symptom intensity was scored by measuring necrotic area $\left(\mathrm{mm}^{2}\right)$ on photos of the leaflet taken 4 days after inoculation, using ImageJ software.

\section{Test on non-detached leaves:}


Four rubber clones (IRCA631, GT1, PB260 and RRIM600) were analyzed in this experiment. In the greenhouse, full non-detached leaves at developmental stage $\mathrm{C}$ were enclosed in bioassay dishes equipped with wet paper (as above), suspended at the appropriate height with nylon strings, and notched on the side for the petiole. The bioassay dishes were made opaque so that incubation could be performed in the dark as in the previous experiments on detached leaves. Each leaflet was gently twisted to place the abaxial face up. Inoculation was performed with a conidial suspension at 10 conidia/ $\mu$ l (20 $\mu$ l per drop, six drops per leaflet). Negative controls were performed with water. All the leaflets were collected 9 days after inoculation, corresponding to the moment when the leaves of the most susceptible clone (IRCA631), inoculated with the wild-type strain, naturally dropped. At least four biological replicates per condition were performed. Necrotic area $\left(\mathrm{mm}^{2}\right)$ was measured from photos of the leaflets taken 9 days after inoculation, using ImageJ software.

\subsection{Complementation with exogenous cassiicolin}

To confirm the role of cassiicolin in virulence, the deletion mutant was complemented with exogenous cassiicolin. CCP and ccp $\triangle$ cas 1 mycelial growth rates were compared in interaction with the susceptible rubber clone IRCA631, by absolute qPCR, in presence or absence of exogenous cassiicolin. Conidia suspensions were prepared as described above and calibrated at 5 conidia/ $\mu$ l. Cassiicolin was purified from $\mathrm{CCP}$ culture filtrate as described previously (Tran et al, 2016). Conidia suspensions $(20 \mu \mathrm{l})$, complemented or not with $10 \mu \mathrm{l}$ of cassiicolin at $5 \mathrm{ng} / \mu \mathrm{l}$ (Tox 5 ), were applied on detached leaves after gentle abrasion of the leaf epidermis to allow penetration and action of the toxin. Negative controls were water with or without toxin, applied also after abrasion. Four biological repeats were performed for each condition. After four days in the dark at $26^{\circ} \mathrm{C}$, three leaf disks $\left(2.2 \mathrm{~cm}^{2}\right)$ per leaflet were sampled at the inoculation points and immediately frozen and ground in liquid nitrogen. Genomic DNA was extracted following the MATAB protocol (Risterucci et al., 2000) and treated with $10 \mathrm{mg} / \mathrm{mL}$ 
of RNase A (Thermo Scientific, Waltham, MA, USA). The standard curve method was used to determine the absolute quantity of the C. cassiicola $\beta$-tubulin gene (Table 2) from $200 \mathrm{ng}$ of CCP or ccp 4 cas 1 DNA, using a StepOne thermocycler (Applied Biosystems, Foster City, CA, USA). qPCR amplification was performed as described above. Standard curve was generated by plotting the values of known quantities of CCP mycelial serially diluted DNA $(100,20,4,0.8$ and $0.16 \mathrm{ng})$ on the corresponding $\mathrm{Ct}$ values. $\mathrm{Ct}$ values of unknown treatedfoliar samples were projected on this created standard curve, thus giving the quantity of target genomic DNA.

\subsection{ELM-based toxicity test}

A phenotyping test based on electrolyte leakage measurements (ELM) was used to assess the sensitivity of rubber clones to $C$. cassiicola exudates, as described previously (Tran et al., 2016). The test was used in two experiments: on the 18 selected clones described above (Table 1) and on 343 genotypes from the bi-parental population PB260 x RRIM600 (Tran et al., 2016). Treatments were filtrates from 21-day-old cultures of various $C$. cassiicola isolates (Table 1) including CCP and the deletion mutant ccp $\triangle$ cas 1 , purified cassiicolin Cas1 at different concentrations $(1,5$ and $10 \mathrm{ng} / \mu \mathrm{l})$, and blank treatments (water and Czapeck culture medium). Leaves were collected at morphogenetic stage C (Hallé and Martin, 1968) and inoculated in vitro with two drops (15 $\mu \mathrm{l}$ each) of each treatment solution applied on the abaxial surface of each leaflet after local abrasion of the lower epidermis $\left(1 \mathrm{~mm}^{2}\right)$. After $48 \mathrm{~h}$ in the dark at $26^{\circ} \mathrm{C}$, two leaf disks $\left(2.2 \mathrm{~cm}^{2}\right)$ per leaflet were sampled at the inoculation point. They were soaked in $5 \mathrm{ml}$ of autoclaved distilled water, in glass tubes, for $24 \mathrm{~h}$, in the dark, at $26^{\circ} \mathrm{C}$. Conductivity of the solution was measured as described previously (Tran et al., 2016), before (C1) and after (C2) autoclaving. Percentage of electrolyte leakage (EL\%) induced by each treatment was calculated as $(\mathrm{C} 1 / \mathrm{C} 2) \times 100$. At least three biological replicates were performed for each clone/treatment combination. 


\subsection{Statistical analyses}

All statistical analyses were performed using R Studio (version 1.1.383). A Student's $t$-test was used to compare size, conidiation and germination of wild-type and mutant strains. Analysis of variance (ANOVA) was followed by Tuckey's HSD (growth kinetics and virulence tests) or SNK (ELM-based toxicity test) post hoc analysis (at risk $\alpha=0.05$ ). The Welch correction was applied when appropriate. All other analyses were performed with a non-parametric Kruskal-Wallis test. A heatmap was generated with the EL\% value matrix data of the clone $\times$ treatment combination using the heatmap. 2 function from the gplots package. Double hierarchical clustering of rows and columns in the heatmap was based on Euclidean distances and used Ward's method of clustering ("ward.D2" in the hclust function).

\subsection{QTL analysis}

QTL associated with sensitivity to fungal exudates were analyzed as previously described (Tran et al., 2016), from the EL\% values measured using the ELM-based test on 343 genotypes from the PB260 × RRIM600 family treated with the purified cassiicolin at $5 \mathrm{ng} / \mu \mathrm{l}$ (Tox5) or with culture filtrates from various $C$. cassiicola isolates, including the wild-type and mutated CCP. QTL were calculated by the Interval Mapping method using MapQTL6 software (Van Ooijen, 2009). They were considered significant at a LoD threshold of 4.2 $(\alpha=0.05)$

\section{Results}

\subsection{Cas 1 deletion in Corynespora cassiicola strain CCP}

In order to settle the role of cassiicolin Cas1 in Corynespora cassiicola pathogenicity in the rubber tree definitively, we created a deletion mutant from the virulent $\mathrm{CCP}$ isolate by replacing the Casl gene with a hygromycin resistance cassette. The deletion construct 
consisted of the hygromycin phosphotransferase gene (hph) framed by Casl 5' and 3' flanking regions, to drive homologous recombination with the native Cas1 gene (Fig. 1).

Eight hygromycin-resistant transformants were selected on PDA medium supplemented with hygromycin B $(60 \mu \mathrm{g} / \mathrm{ml})$. Conformity was checked by PCR compared to the wild-type CCP strain (Fig. 2), using primers listed in Table 2. Successful integration of the hygromycin resistance cassette in all eight transformants was confirmed using primers M13F and M13R, internal to the resistance cassette. To verify the integration site, amplifications were performed with primer P1, targeting the Cas 1 ' flanking region upstream of the cassette integration site, and primer M13R. A product of expected size was obtained for recombined strains 1, 6, 7 and 8, indicating that the cassette was integrated at the proper Cas 1 locus. No amplification was obtained for strains 2, 3, 4 and 5. With primers P1 and P4 (external to the deletion construct) that can amplify both the native $(1,300 \mathrm{bp})$ and recombinant $(2,635 \mathrm{bp})$ Cas 1 locus, three amplification profiles were obtained. For strains 2, 3, 4 and 5, a single band corresponding to the native gene was obtained, thus confirming that the cassette was mistargeted. In strains 1, 7 and 8, both native gene and deletion cassette were amplified, suggesting that the cassette failed to delete the Cas 1 gene even though it was integrated at the proper locus. In addition, a third band (above 3,000 bp) was observed in these strains, which may correspond to the fusion of the native gene and replacement cassette. Only transformant 6 had the expected profile, i.e. a single amplification product corresponding to the hygromycin resistance gene, without any product corresponding to the native gene. Amplification using primers P11 (in Casl CDS) and P4 (in Cas1 3' flanking region) confirmed the persistence of the native Cas 1 gene in all strains except transformant 6 . Finally, sequence conformity of transformant 6 was verified by sequencing the P9/P12 amplicon on both strands.

\subsection{Cas 1 gene expression in CCP wild-type and transformant strains}


We finally verified the deletion by analyzing Cas 1 gene expression in five transformants representing the three insertional profiles described in Figure 2: transformants 1 and 8 carrying both native Casl and the replacement cassette at the proper (Casl) locus; transformants 4 and 5 carrying both native Cas 1 and the replacement cassette at a wrong locus; and transformant 6 with the Cas 1 gene fully replaced by the cassette. Expression was analyzed in germinated conidia. The highest expressions were measured in wild-type CCP and transformants 4 and 5, without significant differences (Fig. 3A). The native Cas 1 gene seems to be completely functional in these two transformants. Conversely, transcripts accumulation was significantly lower in transformants 1 and 8, indicating that Cas 1 gene expression in these strains is negatively impacted - but not totally suppressed — by the hygromycin cassette insertion. Finally, no Cas 1 expression was detected in transformant 6 while the reference gene was normally expressed (Fig. 3B). The conform Cas 1 gene deletion mutant (transformant 6) was renamed ccp Acas1.

\subsection{Physiological comparison of CCP and cepגcas1, in vitro}

We compared wild-type CCP and mutant ccp $\triangle$ cas 1 , in vitro, in terms of mycelium growth, conidiation and germination (Fig. 4 and Table 3). Colony diameter of both strains was measured daily for 7 days on PDA medium with or without the addition of hygromycin. CCP and ccp $\triangle$ cas 1 grow at the same speed, with an increase of $8 \mathrm{~mm} /$ day in average, on PDA and PDA supplemented with hygromycin, respectively (Fig. 4A). Growth of the mutant is not affected by the antibiotic (not shown). After 7 days, mycelium filled the entire Petri dish surface. The young mycelium appears darker in the wild type compared to the mutant (Fig. 4B) and this difference persisted in older mycelium ( $>7$ days). However, this color difference may be accounted for by the presence of hygromycin in the mutant culture medium rather than the absence of Casl gene. Conidiation and percentage of germination after $24 \mathrm{~h}$ were statistically similar between CCP and ccp 4 casl (Table 3). 


\subsection{Pathogenicity of $\operatorname{ccp} \triangle \operatorname{cas} 1$ mutant on detached rubber tree leaves}

$\mathrm{CCP}$ and ccp $\triangle$ cas 1 strains were compared for their virulence on eight rubber clones with contrasted sensitivities, by analyzing the extent of symptoms induced 4 days after application of a conidial suspension ( 5 conidia/ $\mu$ l) on detached rubber tree leaves (Fig. 5 and Supplementary Table S1). As shown previously (Tran et al., 2016), four clones (IRCA18, IRCA631, PB217 and PB260) are susceptible to CCP, with IRCA631 significantly more than the others. The tolerant clones (IRCA41, GT1, RRIC100 and RRIM600) show an average necrosis area lower than $5 \mathrm{~mm}^{2}$ (or no symptoms at all in case of GT1), without significant differences between clones or compared to the water-treated controls (Supplementary Table S1). Mutant ccp $\Delta$ cas 1 induces very low symptoms whatever the clone (average necrosis area below $1 \mathrm{~mm}^{2}$ ), at levels comparable to those induced by wild-type CCP on the tolerant clones or by the control treatment (Supplementary Table S1).

To confirm the loss of virulence in mutant ccp $\Delta$ cas 1 compared to wild-type CCP, inoculation was repeated with a ten-fold higher concentration of conidia (50 conidia/ $\mu$ l) on detached leaves from three contrasted clones IRCA631 (highly susceptible), PB217 (susceptible) and GT1 (tolerant), incubated for up to 7 days post-inoculation (Fig. 6 and Supplementary Table S1). At 4 days post-inoculation (dpi), the ten-fold increase in CCP conidia concentration induces a three and five-fold symptom increase on the susceptible clones (IRCA631 and PB217), respectively, but no increase on the tolerant clone GT1 which remains symptomless. Symptoms induced by the ccp $\Delta$ cas 1 mutant in the susceptible clones at such high conidia concentration remain very low although significantly different compared to the water-treated controls. With longer incubation (7 dpi), symptoms increase significantly whatever the clone, with either CCP or ccp $\triangle$ cas 1 . Nevertheless, the symptoms induced by the mutant remain much lower than those induced by CCP on the susceptible clones, and identical to symptoms on the tolerant clone. While it appears completely healthy at $4 \mathrm{dpi}$, the tolerant clone GT1 
displays low but significant symptoms at 7 dpi compared to the still healthy water-treated control leaves.

A third experiment (Fig. 7 and Supplementary Table S1) was conducted on detached leaves of three contrasted clones (IRC631, GT1 and PB217) with 5 conidia/ $\mu 1$ and observations at 4 dpi, as in Figure 5, except that we gently abraded the leaf epidermis before applying the conidia suspension. In this experiment, abrasion was intended to overcome the cuticle barrier, but it also induced a local wounding effect, in addition to the leaf excision effect. On the susceptible clones IRCA631 and PB217, abrasion strongly increases the intensity of CCPinduced symptoms. The mutant ccp $\triangle$ cas 1 inoculated after abrasion induces symptoms of similar intensity to those induced by CCP without abrasion. However, it remains far less aggressive than CCP when both are applied on abraded leaves of the susceptible clones. Symptoms induced on the tolerant clone GT1 remain low and statistically identical for both strains. Abraded leaves inoculated with water remain symptomless whatever the clone (Supplementary Table S1).

\subsection{Pathogenicity of $\operatorname{ccp} \triangle \operatorname{cas} 1$ mutant on non-detached leaves}

We finally set up an assay allowing controlled inoculation without excision of the leaves while keeping conditions as close as possible to the above-described assay on detached leaves (inoculation with drops of conidia suspension on leaves maintained in plastic boxes under maximal humidity). This assay (Fig. 8 and Supplementary Table S1) allows delayed observation (up to 9 dpi) without senescence effects triggered by leaf excision. Four clones (IRCA631, GT1, PB260 and RRIM600) were inoculated with both strains. Nine days after inoculation, the leaves from IRCA631 inoculated with CCP appear severely damaged and spontaneously dropped off. This pathological abscission, ultimate symptom of the CLF disease, confirms that our test conditions were appropriate for disease development. All the 
other treated leaves (conidia-inoculated or water-treated leaves) from all four clones were manually detached at the same time-point, for comparative analysis. Leaves from the highly susceptible clone IRCA631 inoculated with wild-type CCP were severely damaged. Symptoms on PB260 are comparatively lower, as observed in the detached leaves assay (Fig. 5). The tolerant clones RRIM600 and GT1 show no significant symptoms in response to CCP compared to control (water) treatment. Strikingly, no symptom is observed on the leaves inoculated with ccp $\Delta$ casl, whatever the clone, except for a few pinpoint symptoms on IRCA631 that are not statistically significant compared to those induced by the control treatment or by $\mathrm{CCP}$ on the tolerant clones.

\subsection{Complementation of $\operatorname{ccp} \Delta \operatorname{cas} 1$ with exogenous cassiicolin}

The previous inoculation experiments demonstrated the significant loss of virulence of ccp $\triangle$ cas 1 compared to the wild-type CCP, in several rubber clones, suggesting that cassiicolin is required for virulence in these clones. To rule out any functional defect of the fungus due to either a spontaneous mutation or ectopic insertion in the fungal genome of another copy of the deletion cassette, we conducted a complementation experiment with exogenous cassiicolin. We inoculated both strains on the susceptible clone IRCA631, with or without addition of purified cassiicolin at $5 \mathrm{ng} / \mu \mathrm{l}$ (Tox5), on abraded leaves. It should be underlined that gentle abrasion of the epidermis before application of the toxin is required for toxin action (Supplementary Figure). We then monitored the mycelial development in the leaf tissues after four days, by absolute qPCR, with primers targeting the $C$. cassiicola housekeeping $\beta$ tubulin gene. (Fig. 9). The absence of amplification in the control leaves (treated with water or water+Tox5) confirms the specificity of the primers for the fungal $\beta$-tubulin gene. A low amount of DNA was detected for ccp 4 cas 1 without cassiicolin, but it was found not significant compared to the controls, suggesting that the mutant is blocked soon after inoculation or that its development is very slow. In the presence of cassiicolin 
(ccp $\Delta$ cas $1+$ Tox5), the growth of the mutant was six-fold higher and statistically identical to that of the wild-type CCP. Exogenous cassiicolin had no additive effect on CCP growth, suggesting that the production of endogenous cassiicolin by CCP was sufficient to allow optimal development of the fungus in the plant tissues. To conclude, complementation with exogenous cassiicolin restored the capacity of the mutant to develop rapidly inside the rubber tree leaves.

\subsection{Compared toxicity of $\mathrm{CCP}$ and $\operatorname{ccp} \triangle \operatorname{cas} 1$ culture filtrates on eighteen rubber clones}

We previously developed an indirect phenotyping test to predict the susceptibility of rubber clones to $C$. cassiicola from their sensitivity to fungal exudates (Tran et al., 2016). This test uses electrolyte leakage measurements (ELM) to quantify the leaf damages induced by fungal culture filtrates or purified Cas1 toxin applied on detached leaves, after local abrasion of the lower epidermis. In this test, abrasion is required for toxin action; indeed, application of exogenous toxin on intact leaves (without abrasion) induces no significant electrolyte leakage compared to the blank (water) treatment, as shown here on the susceptible clone PB260 (Supplementary Figure). We compared the toxicity of culture filtrates from $c c p \Delta c a s$, CCP and other C. cassiicola isolates (Table 1) on 18 rubber clones from plantations in the Ivory Coast. Purified cassiicolin at three concentrations (Tox1, Tox5 and Tox10) was used as reference. Blank treatments were water (Tox0) and mock-inoculated culture medium $(\mathrm{Cz})$. ANOVA performed on the whole dataset shows significant effects of clones, treatments and clone $\times$ treatment interaction $(\mathrm{p}<0.001$, Supplementary Table S2), explaining $88 \%$ of the total variance $\left(\mathrm{R}^{2}\right)$, with contributions of $34 \%, 30 \%$ and $24 \%$, respectively. Double hierarchical clustering was used to identify clusters of clones (CL) and treatments (Tr) based on their sensitivity/toxicity profiles (Fig. 10 and Supplementary Table S3).

As shown previously on a smaller dataset (Tran et al., 2016), CCP filtrate clusters with the purified cassiicolin at 5 and $10 \mathrm{ng} / \mu \mathrm{l}$ (Tox 5 and Tox 10 , respectively), suggesting that Cas 1 is 
an important factor of CCP filtrate toxicity. It is more distantly associated with two isolates (CNig404 and CCi501, cluster Tr3) of the same type C/Cas1, i.e. phylogenetically related to CCP (group C) and carrying the same Cas1 gene (toxin class Cas1). The mutant ccp 4 cas 1 filtrate is on average significantly less aggressive than the wild-type CCP filtrate but, interestingly, its toxicity is still strong compared to the blank treatments Tox0 and $\mathrm{Cz}$ or to filtrates of low average toxicity clustered in $\operatorname{Tr} 5$ and $\operatorname{Tr} 6$. The mutant clusters in $\operatorname{Tr} 4$ with two A4/Cas0 isolates of moderate filtrate toxicity, CCi403 and CCi434. Cluster Tr1 contains four filtrates of high mean aggressiveness: three from type A4/Cas0 isolates and one from a type C/Cas1 isolate (CCAM3). The A4/Cas0 type appears to be highly diverse in terms of filtrate toxicity, with representatives in three different clusters.

Deletion of the Cas1 gene affected the ELM response differentially depending on the clones. The loss of toxicity is globally substantial in CL2 clones and is particularly marked in PB254. It seems that sensitivity to the filtrates in this group of clones is mostly due to sensitivity to Cas1. By contrast, CL1 clones are more sensitive on average but they seem to react to factors other than cassiicolin, since all of them remain highly sensitive to the mutant filtrate. On tolerant clones (cluster CL3, including among others GT1, RRIM600 and IRCA41), CCP and ccp $\triangle$ cas 1 filtrates display comparatively similar low-to-medium toxicity.

These results suggest that (1) sensitivity to cassiicolin is clone-dependent and (2) effectors other than cassiicolin are secreted by CCP in the culture medium, causing toxicity (electrolyte leakage) on specific clones. Some of these factors may be shared with A4/Cas0 isolates in addition to other $\mathrm{C} / \mathrm{Cas} 1$ isolates.

\subsection{QTL associated with sensitivity of rubber tree to CCP and $\operatorname{ccp} \triangle \operatorname{cas} 1$ culture filtrates}

We previously demonstrated the polygenic determinism of rubber tree sensitivity to cassiicolin by phenotyping a population of 191 genotypes (Pop1) from the PB260 $\times$ RRIM600 F1 progeny, using the ELM-based test (Tran et al., 2016). Two QTL (g2-26 and 
g4-95) were detected, on the linkage groups 2 and 4. Both were associated with the purified toxin Cas1 as well as the CCP filtrate, strongly suggesting that Cas1 may play a role in the toxicity of the CCP filtrate. To confirm this result, we phenotyped the same progeny with filtrate from the deletion mutant ccp $\triangle c a s 1$, comparatively to filtrates from $\mathrm{CCP}$ and other isolates of various types (Table 4). We analyzed two populations from the same progeny, planted in different locations, to strengthen our results. The two previously identified QTL are confirmed, with similar percentages of explained phenotypic variance $\left(12<\mathrm{R}^{2}<17\right)$, stressing the robustness of this result obtained on two different sites. Surprisingly, a third QTL (position g5-73, $\mathrm{R}^{2}=14$ ) was found associated with the response to CCP filtrate on Pop2, but not with the response to the purified cassiicolin Tox5. However, a LoD score peak under the significance threshold (around 2.5) was detected at the same position with Tox5, on both Pop1 $\left(\mathrm{R}^{2}=4\right)$ and Pop2 $\left(\mathrm{R}^{2}=8\right)$, and with CCP filtrate on Pop2 $(\mathrm{R} 2=6)$. No peak was detected at that position with ccp $\triangle$ cas 1 filtrate. This suggests that the QTL at position $\mathrm{g} 5-73$ is probably associated with cassiicolin rather than with another effector of CCP filtrate. Whether the discrepancy between the two experiments (on Pop1 and Pop2) is due to environmental differences between the two sites or sampling bias is unclear. With ccp $\Delta$ cas 1 mutant filtrate, none of the CCP- or Tox5-associated QTL were detected, thus unambiguously confirming the involvement of these loci in rubber tree sensitivity to cassiicolin Cas1. Instead, two new QTL were found (g13-11 and g9-62). Interestingly, these new QTL are also detected with filtrates from isolates $\mathrm{CCi} 403$ and $\mathrm{CCi} 434$ respectively, both type A4/Cas0 and part of the same treatment cluster $(\mathrm{Tr} 4$, Fig. 10). The others A4/Cas0 filtrates reveal various QTL patterns: filtrates CCi13, CCi6 and CSRi5, of the same treatment cluster $(\operatorname{Tr} 1)$, reveal one common QTL (g4-32), while filtrates of treatment cluster Tr5 (of low average toxicity) reveal either a distinct pattern (CIND3) or no QTL (CL16). All filtrates of type C/Cas1 reveal the expected significant Cas1-associated QTL (g2-26 and g4-95), except filtrate from CCAM3, isolate in 
which the Cas1 gene expression level post-inoculation was lower compared to CCP (Déon et al., 2012a).

\section{Discussion}

\subsection{Cassiicolin Cas1 is a necrotrophic effector required for the successful development of $C$. cassiicola strain CCP in susceptible rubber tree clones}

A number of converging results suggest that Cas1 cassiicolin plays an important role in the CLF disease of the rubber tree (Barthe et al., 2007; Breton et al., 2000; de Lamotte et al., 2007; Déon et al., 2012a; Déon et al., 2012b; Lopez et al., 2018). Here, using a Cas1 deletion mutant, we functionally demonstrate the essential role of this toxin for the virulence of the highly aggressive strain CCP.

We obtained a single conform mutated strain (ccpAcas1) in which the Cas1 gene was fully removed by homologous recombination (Fig. 2 and 3). In vitro analysis showed that the deletion of the Cas1 gene affects neither the mycelium growth speed nor the sporulation or germination capacity of the fungus (Fig. 4 and Table 3), all of which are parameters that could indirectly impair its virulence.

Casl deletion induced a partial decrease or total loss of virulence depending on the test conditions, in all the susceptible rubber clones tested (Fig. 5, 6, 7 and 8). The mutant ccp $\Delta$ cas 1 appears fully avirulent when inoculated on intact (non-detached) leaves of two susceptible clones, even at 9 dpi on the highly susceptible IRCA631 (Fig. 8). This strongly suggests that no effector beside cassiicolin is required for necrotrophy on these clones. On detached leaves however, we measured low but significant residual symptoms with the deleted strain ccp $\triangle$ cas 1 at high conidia concentration, especially after longer incubation times

(Fig. 6). Assuming that no other effector contributes to necrotrophy, at least in the clone 
IRCA631 common to both experiments, we can raise the hypothesis that leaf excision activated senescence processes in the leaf tissue, thus allowing the saprotrophic development of the deletion mutant. Indeed, excised leaves immediately undergo senescence, characterized by a decrease in chlorophyll, which starts immediately in darkness (Biswal et al., 1983; Kar et al., 1993; Thimann and Satler, 1979). Abscission and wounding involve common signaling pathways in which ethylene and jasmonate play a central role (Bari and Jones, 2009), leading to local cell death as a defense mechanism. These signals are thought to trigger a shift toward saprotrophy in the endophytic fungi inhabiting the leaf tissues (Promputtha et al., 2007; Suryanarayanan, 2017; U'Ren and Arnold, 2016). Our results suggest that the CCP isolate is equipped both for necrotrophy, thanks to cassiicolin, and for saprotrophy, thanks to other factors potentially activated during leaf senescence, including in the cassiicolin-deleted strain.

To test the wounding effect and its possible interaction with cassiicolin further, we locally abraded the epidermis of detached leaves prior to inoculation with conidia (Fig. 7), in the same way as we tested filtrates toxicity with the ELM-based method (Fig. 10). Abrasion alone followed by a blank treatment with water induces no visible symptom in the inoculation experiment (Supplementary Table S1), and the lowest average electrolyte leakages in the ELM-based test (Fig. 10). Abrasion is expected to generate DAMPs (Damage-Associated Molecular Patterns) that trigger basal plant defenses known as DAMP-Triggered Immunity or DTI (Heil and Land, 2014; Mengiste, 2012; Pandey et al., 2016; Zipfel, 2014). However, DTI was clearly not able to prevent invasion by the fungus in our study. To the contrary, abrasion increases CCP-induced symptoms, markedly in the susceptible clones but also, moderately, in the tolerant clone GT1. It also favors the development of the deletion mutant, although the symptoms remain moderate, with no strong difference between susceptible and tolerant clones, compared to CCP (Fig. 7). Here again, the wound effect observed with the deletion 
mutant could be accounted for saprotrophy. By contrast, the marked clone-dependent wound effect observed with CCP suggests a synergy between cassiicolin and wounding.

Application of purified toxin on abraded leaves induced significant electrolyte leakages, proportional to the toxin concentration (Fig. 10). This effect was clone-dependent, which implies that clone-specific sensitivity factors are required for the action of the toxin. Cassiicolin without abrasion fails to induce symptoms (Supplementary Figure) suggesting that it cannot pass the physical barriers of the leaf without wound-disruption or active fungal intervention. Cassiicolin per se is thus unlikely to play a direct role in penetration of the cells. Other fungal molecules may be required, such as hydrolytic enzymes. We previously showed that a number of fungal genes encoding carbohydrate-active enzymes (CAZymes) are upregulated during early infestation (24 and $48 \mathrm{~h}$ post-inoculation) of the susceptible clone PB260 by the isolate CCP (Lopez et al., 2018). They may participate in cell wall hydrolysis and thus fungal penetration.

We demonstrated in this study that in vivo complementation of the deletion mutant with exogenous cassiicolin (applied after leaf abrasion) restored its capacity to colonize the plant tissues with the same efficiency as the wild-type strain (Fig. 9). Cassiicolin clearly acts as a necrotrophic effector aimed at degrading the rubber tree leaf tissues (as exemplified by the visible necrosis and electrolyte leakages induced by the purified toxin), for the benefit of the fungus development. In the absence of cassiicolin, the fungus may rely on leaf senescence or wounding for acquiring nutrients necessary to its development (saprotrophy), although with a much lower efficiency. The mechanisms by which cassiicolin operates such cellular degradations are still unknown. The toxin may target vital functions in the plant cells or interfere with the plant defenses. The synergy that we observed between cassiicolin and wounding suggests that cassiicolin may amplify (or divert) the defense reactions primed by 
wounding, towards programmed cell death, favorable to $C$. cassiicola development owing to its necrotrophic life style. In the inoculation experiment on intact (non-detached) leaves, it can be assumed that immunity, in the absence of wounding, is triggered by MAMPs (MicrobeAssociated Molecular Patterns) rather than DAMPs. Unlike the wild-type strain, the cassiicolin-deleted strain is unable to overcome such immunity, thus further supporting the idea that cassiicolin is able to manipulate both DAMP- and MAMP-induced defense pathways towards increased cell death.

The clone-dependent response observed with CCP and the purified toxin implies that clonespecific susceptibility factors are required for the action of the toxin. Our results confirm that cassiicolin is a necrotrophic effector required for the virulence of CCP in susceptible rubber clones carrying (an) appropriate susceptibility factor(s), in agreement with the NETS (necrotrophic effector-triggered susceptibility) model (Liu et al., 2015; Tan et al., 2010).

\subsection{Effectors other than cassiicolin}

The objective of this study was not only to confirm the role of cassiicolin in virulence on the rubber tree but also to evaluate the potential contribution of other effectors in this virulence. In a previous in silico analysis, we demonstrated the presence of 2,870 putative effectors in the CCP genome, of which 92 were differentially expressed (mostly up-regulated) during the compatible interaction with the susceptible clone PB260 (Lopez et al., 2018). Here we show that deletion of the Casl gene suppresses all virulence when inoculation is performed on nondetached leaves, suggesting that in this context, there is no other effector able to significantly drive virulence in the absence of cassiicolin. However, as discussed above, some other effectors may rather be involved in saprotrophy, allowing a slow development of the fungus in the decaying tissues of senescing or wounded leaves, 
We also demonstrated, in two independent ELM-based experiments, that Cas 1 deletion significantly modified CCP filtrate toxicity profile over a range of clones. In the first experiment on 18 selected clones (Fig. 10), some are sensitive to the CCP filtrate but weakly or not sensitive to the ccp $\triangle$ cas 1 filtrate; other display similar responses to both filtrates, suggesting that their sensitivity in the conditions of the ELM-based test was Cas1independent. In the second experiment, on 343 progenies from the PB260 × RRIM600 family (Table 4), ccp $\triangle$ cas 1 filtrate no longer reveals the two Cas1-associated QTL, detected with either the purified cassiicolin, CCP filtrate, or other Cas1-producing filtrates. However, the mutant filtrate retains enough toxicity to reveal two new QTL. In both experiments (Fig. 10 and Table 4), ccp 4 cas 1 is closely associated with two A4/Cas0 isolates (CCi403 and CCi434) based on filtrate toxicity profiles, suggesting that they may share common effectors. In CCP filtrate, cassiicolin may mask or suppress the effect of other common effectors. Other A4/Cas0 isolates display different toxicity profiles (Fig. 10 and Table 4), suggesting a different composition in effectors able to confer strong filtrate toxicity on specific clones, independently of Cas1.

In Pyrenophora tritici-repentis (Ptr), pathogen of wheat, deletion of the gene encoding the host selective toxin ToxA obscured the expression of symptoms caused by other toxins, in specific cultivars (Manning and Ciuffetti, 2015). The authors raised the hypothesis that ToxA gene expression may cause a repression of other toxin-encoding genes. To test this hypothesis in our pathosystem, it would be interesting to compare CCP and ccp $\Delta c a s 1$ transcriptomes in order to identify genes differentially expressed following cas 1 deletion.

In our study, QTL detection with CCP and ccp 4 cas 1 filtrates, together with the purified cassiicolin Cas1, unambiguously confirms that at least two loci are associated with the sensitivity to Cas1 in the PB260 x RRIM600 family, in the conditions of the ELM-based test. 
It is noteworthy that, in many pathosystems involving necrotrophic pathogens, NEs (necrotrophic effectors) usually interact with single matching plant receptors to mediate NETS (De Wit et al., 2016). However, intermediate interactors may sometimes be involved to modulate the intensity of the response ( $\mathrm{Lu}$ et al., 2014). Further investigation of Cas1 molecular targets may help understanding the polygenic determinism of rubber tree sensitivity to Cas1.

\section{Conclusions}

Our results confirm that cassiicolin is a necrotrophic effector required for the virulence of CCP in susceptible rubber clones carrying specific susceptibility factors, in agreement with the NETS (necrotrophic effector-triggered susceptibility) model. Other effectors secreted by CCP may be involved either in saprotrophy, in senescing tissue or, putatively in necrotrophy in yet unknown clones or hosts with matching susceptibility factors. Demonstrating the role of cassiicolin Cas1 in the virulence of CCP opens the way for the development of effector-based selection of rubber clones with improved tolerance to CLF.

\section{Acknowledgments}

The authors would like to thank Thomas Guillemette and Benoit Calmes, from Angers University (France), for providing plasmid pCB1636 and procedures for targeted gene deletion in fungi. They also thank Christelle Boisselet, Clémence Morand and Amélie Coston for assistance in plant maintenance in the green house at Université Clermont Auvergne. Finally, the authors would like to acknowledge the technical teams at SOGB and SAPH plantations for assistance in field and laboratory experiments in Côte d'Ivoire. 


\section{Funding}

Researches were supported by IFC (“Institut Français du Caoutchouc”, Paris, France), the companies Michelin (http://www.michelin.com/), SIPH ("Société Internationale de Plantations d'Hévéa"), and Socfin (http://www.socfin.com/). This support includes salary for SR, DMT and MD. The plantations SOGB ("Société des Caoutchoucs de Grand-Béréby", belonging to the SOCFIN group) and SAPH-Toupah ("Société Africaine de Plantation d'Hévéa", belonging to the SIPH group), provided access and logistic assistance for field and lab experiments in Côte d'Ivoire. 


\section{Tables}

Table 1 - Corynespora cassiicola isolates used in this study.

\begin{tabular}{cclcc}
\hline $\begin{array}{c}\text { Corynespora } \\
\text { cassiicola } \text { strains }\end{array}$ & $\begin{array}{c}\text { Geographical } \\
\text { origin }\end{array}$ & Isolate type & $\begin{array}{c}\text { Isolation } \\
\text { year }\end{array}$ & References \\
\hline CCP & Philippines & C/Cas1 & 2000 & Breton et al., 2000 \\
CIND3 & India & A4/Cas0 & 2012 & Déon et al., 2014 \\
CSRi5 & Sri Lanka & A4/Cas0 & 2012 & Déon et al., 2014 \\
CLN16 & Malaysia & A4/Cas0 & 2012 & Déon et al., 2014 \\
CCi6 & Ivory Coast & A4/Cas0 & 2012 & Déon et al., 2014 \\
CCi13 & Ivory Coast & A4/Cas0 & 2012 & Déon et al., 2014 \\
CSB16 & Malaysia & B4/Cas5 & 2012 & Déon et al., 2014 \\
TSB1 & Malaysia & B4/Cas5 & 2012 & Déon et al., 2014 \\
CCAM3 & Cameroon & C/Cas1 & 2012 & Déon et al., 2014 \\
CTHA3 & Thailand & F1/Cas0 & 2012 & Déon et al., 2014 \\
CCi403 & Ivory Coast & A4/Cas0 & 2014 & / \\
CCi434 & Ivory Coast & A4/Cas0 & 2014 & / \\
CCi402 & Ivory Coast & A4/Cas2 & 2014 & / \\
CCi449 & Ivory Coast & B4/Cas0 & 2014 & / \\
CCi416 & Ivory Coast & B4/Cas5 & 2014 & / \\
CNig404 & Ivory Coast & -/Cas4* & 2014 & / \\
\hline
\end{tabular}

* This strain did not fall into a supported phylogenetic clade 
Table 2 - Primers used in this study.

\begin{tabular}{|c|c|c|}
\hline Name & Sequence $\left(5^{\prime}, \ldots 3^{\prime}\right)$ & Description \\
\hline \multicolumn{3}{|c|}{ Construction and characterization of the Cas 1 deletion mutants } \\
\hline $\begin{array}{l}\mathrm{P} 1 \\
\mathrm{P} 2\end{array}$ & $\begin{array}{c}\text { GATCGGGAGGCGTACTATC } \\
\text { GCGCTCACTGGCCGTCGTTTTACAATGTATAGGACAGATTTTCAAGA }\end{array}$ & $\begin{array}{l}\text { Amplify the } 5 \text { ' flanking sequence of } \\
\text { Cas } 1 \text { gene }(494 \mathrm{bp})\end{array}$ \\
\hline $\begin{array}{l}\mathrm{P} 3 \\
\mathrm{P} 4\end{array}$ & $\begin{array}{c}\text { GGTCATAGCTGTTTCCTGTGTGAAGCGGCCCACAAGATAGTGTA } \\
\text { CTGCCTAACGTATTTGCGACA }\end{array}$ & $\begin{array}{l}\text { Amplify the 3' flanking sequence of } \\
\text { Cas } 1 \text { gene (529 bp) }\end{array}$ \\
\hline $\begin{array}{l}\text { M13F } \\
\text { M13R }\end{array}$ & $\begin{array}{l}\text { TGTAAAACGACGGCCAGTGAGCGC } \\
\text { TTCACACAGGAAACAGCTATGACC }\end{array}$ & $\begin{array}{l}\text { Amplify the HygB-resistance gene from } \\
\text { pCB1636 (1,660 bp) }\end{array}$ \\
\hline $\begin{array}{l}\text { P7 } \\
\text { P8 }\end{array}$ & $\begin{array}{c}\text { CGGGAGCTTTGGATGGCGA } \\
\text { GACAGACCCTTGCAGTTTTTC }\end{array}$ & $\begin{array}{l}\text { Amplify the full deletion cassette }(2,592 \\
\text { bp) }\end{array}$ \\
\hline $\begin{array}{l}\text { P9 } \\
\text { P10 }\end{array}$ & $\begin{array}{l}\text { AAGGGCCGGAAGAAGATACGA } \\
\text { CAGCAACGGCTGCTACAAAAG }\end{array}$ & $\begin{array}{c}\text { Amplify } 5^{\prime} \text { flanking region and partial } \\
\text { CDS of Cas I gene ( } 684 \mathrm{bp})\end{array}$ \\
\hline $\begin{array}{l}\mathrm{P} 11 \\
\mathrm{P} 12\end{array}$ & $\begin{array}{l}\text { CTGCTTTTGTAGCAGCCGTTG } \\
\text { TCGTGAGGGCAGAAGAAGCTA }\end{array}$ & $\begin{array}{l}\text { Amplify partial CDS and 3' flanking } \\
\text { region of Cas } 1 \text { gene }(1,425 \mathrm{bp})\end{array}$ \\
\hline $\begin{array}{l}\text { HygR-F3 } \\
\text { HygR-R1 } \\
\text { PTrpC-F1 } \\
\end{array}$ & $\begin{array}{c}\text { CGTTATGTTTATCGGCAC } \\
\text { CATCGACCCTGCGCCCAA } \\
\text { GGCTTGGCTGGAGCTAGTG }\end{array}$ & Sequencing HygB-resistance gene \\
\hline \multicolumn{3}{|c|}{ Identification of Cas1 gene expression } \\
\hline $\begin{array}{l}\text { Cc-qEF1a-F1 } \\
\text { Cc-qEF1a-R1 }\end{array}$ & $\begin{array}{l}\text { CACCGTCATTGACGCCCCC } \\
\text { GCCTCGAACTCACCAGTACC }\end{array}$ & $\begin{array}{l}\text { Amplify the } E F 1 \alpha \text { gene from CCP } \\
\text { genome }\end{array}$ \\
\hline $\begin{array}{l}\text { Cc-qActin-F1 } \\
\text { Cc-qActin-R1 }\end{array}$ & $\begin{array}{l}\text { CATTGTCATGTCTGGTGGTA } \\
\text { TGATCTTGACCTTCATCGAG }\end{array}$ & $\begin{array}{l}\text { Amplify the Actin gene from CCP } \\
\text { genome }\end{array}$ \\
\hline $\begin{array}{l}\text { Cc-Btub-F1 } \\
\text { Cc-Btub-R1 }\end{array}$ & $\begin{array}{l}\text { TGGAGCGCATGAACGTCTACT } \\
\text { TCGGGACGGAAAAGCTGACC }\end{array}$ & $\begin{array}{c}\text { Amplify the } \beta \text {-tubulin gene from CCP } \\
\text { genome }\end{array}$ \\
\hline $\begin{array}{l}\text { Cc-qCas1-F1 } \\
\text { Cc-qCas1-R1 }\end{array}$ & $\begin{array}{c}\text { ACTTGCGTAAGCTGTGTCAATTTCG } \\
\text { CATCCCGAACAAGCCCAAGA }\end{array}$ & $\begin{array}{l}\text { Amplify the Cas } 1 \text { gene from } \mathrm{CCP} \\
\text { genome }\end{array}$ \\
\hline
\end{tabular}


Table 3 - In vitro comparison of mycelial growth, conidiation and germination rates between CCP and ccpAcas1.

\begin{tabular}{cccc} 
Strain & $\begin{array}{c}\text { Colony diameter of seven } \\
\text { days-old cultures }(\mathbf{m m})\end{array}$ & $\begin{array}{c}\text { Conidiation } \\
(\text { conidia/ } \boldsymbol{\mu l})\end{array}$ & Germination $(\%)$ \\
\hline $\mathrm{CCP}$ & $56 \pm 1.2 \mathrm{a}$ & $426 \pm 56 \mathrm{a}$ & $72 \pm 9 \mathrm{a}$ \\
ccp 4 cas 1 & $58 \pm 1.0 \mathrm{a}$ & $479 \pm 42 \mathrm{a}$ & $70 \pm 6 \mathrm{a}$ \\
\hline
\end{tabular}

Data are given as means of four independent replicates with standard deviation. Statistical analysis used a

Student's $t$-test. Letters indicate the significance of between-group differences (Student's $t$-test, $\alpha=0.05$ ). 
Table 4 - QTL associated with sensitivity to $C$. cassiicola exudates, detected from the PB260 x RRIM600 F1 family.

\begin{tabular}{|c|c|c|c|c|c|c|c|c|c|c|c|c|c|c|c|c|}
\hline \multirow[t]{2}{*}{ Treatments } & \multirow[t]{2}{*}{ Type } & \multirow[t]{2}{*}{ Population } & \multicolumn{14}{|c|}{ QTL } \\
\hline & & & g2-26 & g3-11 & g4-32 & g4-95 & g5-73 & g6-26 & g9-62 & g9-122 & g12-53 & g13-102 & g14-64 & g16-11 & g16-77 & g18-87 \\
\hline \multirow{2}{*}{ Tox5 } & \multirow{2}{*}{ C/Cas1 } & Pop1 & 17 & - & - & 11 & - & - & - & - & - & - & - & - & - & - \\
\hline & & Pop2 & 17 & - & - & 17 & - & - & - & - & - & - & - & - & - & - \\
\hline \multirow{2}{*}{$\mathrm{CCP}$} & \multirow{2}{*}{ C/Cas1 } & Pop1 & 12 & - & - & 12 & - & - & - & - & - & - & - & - & - & - \\
\hline & & Pop2 & 12 & - & - & 13 & 14 & - & - & - & - & - & - & - & - & - \\
\hline ccp $\Delta$ cas1 & C/Cas0 & Pop2 & - & 16 & - & - & - & - & 11 & - & - & - & - & - & - & - \\
\hline CCi501 & C/Cas1 & Pop2 & 16 & - & - & 19 & - & - & - & - & - & - & - & - & - & - \\
\hline CNig404 & C/Cas1 & Pop2 & 20 & - & - & 12 & - & - & - & - & - & - & - & - & - & - \\
\hline CCAM3 & C/Cas1 & Pop1 & - & - & - & - & - & - & - & - & 13 & 11 & - & - & - & - \\
\hline CCi434 & A4/Cas0 & Pop2 & - & - & - & - & - & 13 & 11 & - & - & - & - & - & - & - \\
\hline CCi403 & A4/Cas0 & Pop2 & - & 13 & - & - & - & 10 & - & - & - & - & - & 12 & - & - \\
\hline CIND3 & A4/Cas0 & Pop2 & - & - & - & - & - & - & - & 11 & - & - & - & - & 11 & - \\
\hline CCi13 & A4/Cas0 & Pop1 & - & - & 14 & - & - & - & - & - & - & - & - & - & - & - \\
\hline CCi6 & A4/Cas0 & Pop1 & - & - & 11 & - & - & - & - & - & - & - & - & - & - & - \\
\hline CSRi5 & A4/Cas0 & Pop1 & - & - & 12 & - & - & - & - & - & - & 11 & - & - & - & - \\
\hline CSB16 & B4/Cas5 & Pop1 & - & - & - & - & - & - & - & - & - & 13 & - & - & - & - \\
\hline TSB1 & B4/Cas5 & Pop1 & - & - & - & - & - & - & - & - & - & - & 16 & - & - & - \\
\hline CLN16 & A4/Cas0 & Pop2 & - & - & - & - & - & - & - & - & - & - & - & - & - & - \\
\hline СТНАЗ & F1/Cas0 & Pop2 & - & - & - & - & - & - & - & - & - & - & - & - & - & - \\
\hline \multirow{2}{*}{$\mathrm{Cz}$} & & Pop1 & - & - & - & - & - & - & - & - & - & - & - & - & - & - \\
\hline & & Pop2 & - & - & - & - & - & - & - & - & - & - & - & - & - & - \\
\hline \multirow{2}{*}{ Tox0 } & & Pop1 & - & - & - & - & - & - & - & - & - & - & - & - & - & - \\
\hline & & Pop2 & - & - & - & - & - & - & - & - & - & - & - & - & - & - \\
\hline
\end{tabular}

Progenies from the PB260 $\times$ RRIM600 F1 family were planted in two populations at SOGB (Pop1) and SAPH-Toupah (Pop2). Treatments (column 1) were purified cassiicolin Cas1 at $5 \mathrm{ng} / \mu \mathrm{l}$ (Tox5), culture filtrates from various isolates types including the wild-type CCP and deletion mutant $c c p \Delta C a s 1$, and blanks (water Tox0 and culture medium Cz). Sensitivity to the treatments was estimated as the percentage of induced electrolyte leakage (\%EL). QTL were considered significant at the LoD threshold of $4.2(\alpha=0.05)$. QTL are named by the number of the linkage group $(\mathrm{g})$ on which they are located, and their position (in bold). Numbers are percentage of explained phenotypic variance $\left(\mathrm{R}^{2}\right)$. 


\section{Figure captions}

\section{Figure 1 - Construction of the Cas 1 gene deletion cassette.}

Adapted from Yu et al (Yu et al., 2004). Primer details are given in Table 2. (A) PCR amplification of the cassette elements: the hygromycin resistance gene (hph gene under control of the trpC fungal promoter) was amplified with primers M13F and M13R from the pCB1636 plasmid (Sweigard et al., 1995); the 5' and ' ' flanking regions of the Cas 1 gene were amplified with the primer pairs $\mathrm{P} 1 / \mathrm{P} 2$ and $\mathrm{P} 3 / \mathrm{P} 4$, respectively. Primers $\mathrm{P} 2$ and $\mathrm{P} 3$ carried 24 bases complementary to the ends of the $h p h$ gene (striped square). (B) PCR assembly of the elements, with the overhanging chimerical extensions acting as primers. (C) PCR amplification of the full deletion cassette using primers P7 and P8. (D) Replacement of the native Casl gene by the hygromycin resistance gene (hph gene) on the CCP genome, by homologous recombination.

\section{Figure 2 - PCR analysis of the hygromycin-resistant transformants.}

PCR amplification from genomic DNA of 8 hygromycin-resistant transformants (lanes 1 to 8 ) and the wild-type (lane CCP) using four primer pairs (M13F/M13R, P1/M13R, P1/P4 and P11/P4). A negative control was performed using water (lane NC). Pair M13F/M13R amplifies the hygromycin cassette $(1,660 \mathrm{bp})$. P1/M13R was used to verify the cassette insertion site (2,133 bp). P1 and P4, located in Cas1 flanking regions, external to the [P7-P8] deletion cassette, amplified the native Cas 1 gene (1,300 bp) and/or the deletion cassette (2,638 bp). P11/P4 identifies the native Cas 1 gene only (795 bp). PCR products were separated on $1 \%$ agarose gels by electrophoresis in $0.5 \mathrm{X}$ TAE buffer supplemented with Sybr Safe $(0.1 \mu \mathrm{g} / \mathrm{ml})$, and photographed under UV light. $1 \mathrm{~kb}$ DNA ladder (Promega, Madison, WI, USA) was used as molecular-weight size marker (lane $1 \mathrm{~kb}$ ).

Figure 3 - Detection of Cas 1 cDNA on germinating spores of CCP and transformants 1, 4, 5,

\section{6, 8 after 24 hours.}

(A) Real-time quantitative PCR analysis of Casl gene transcript accumulation. Normalization was performed using three reference genes from Corynespora cassiicola: EF1 $\alpha$, Actin and $\beta$-tubulin 
(Table 2). Error bars represent standard error of the mean for at least three biological replicates.

Data were analyzed using a Kruskal-Wallis test. Groups with the same letters are not significantly different $(\alpha=0.05)$.

(B) Agarose gel electrophoresis (1\%) of the real-time quantitative PCR products from Cas1 (top) and EFl $\alpha$ (bottom) gene in $0.5 \mathrm{X}$ TAE buffer supplemented by Sybr Safe $(0.1 \mu \mathrm{g} / \mathrm{ml})$, photographed under UV light. Purified water was used as negative control (NC). 100-bp DNA ladder (Promega, Madison, WI, USA) was used as molecular-weight size marker (lane 100 pb).

\section{Figure 4 - Comparison of mycelium size and shape of CCP and ccp 4 cas1 strains.}

The mycelium from the CCP strain was cultivated on PDA medium supplemented with lactic acid $(0.02 \%)$. The ccp $\Delta$ cas 1 mutant was cultivated on PDA medium supplemented with lactic acid $(0.02 \%)$ and hygromycin B $(60 \mu \mathrm{g} / \mathrm{ml})$. Both strains were incubated in the dark at $26^{\circ} \mathrm{C}$. Diameters of mycelia were measured daily for 7 days (A), then photographed (B). Size of the initial mycelial plug $(5 \mathrm{~mm})$ was subtracted such that all measurements began at $0 \mathrm{~mm}$. Data were analyzed using ANOVA. Letters indicate the significance of between-group differences (Tuckey's HSD test, $\alpha=0.05)$.

Figure 5 - Virulence of mutant ccpAcas1 and wild-type CCP on detached leaves from eight rubber clones.

For each clone, five leaves were treated with 6 drops each of conidia suspension at 5 conidia/ $\mu 1$ from either CCP or ccp 4 cas 1 . For each strain/clone combination, symptom intensity was scored four days after spore inoculation as the mean surface of necrotic tissue $\left(\mathrm{mm}^{2}\right)$, for at least four biological replicates. Water-treated controls did not induce any symptoms (Supplementary Table S1). Data were analyzed using Welch's ANOVA. Letters indicate the significance of betweengroup differences (Tuckey's HSD test, $\alpha=0.05$ ).

Figure 6 - Effect of spore concentration on CCP and ccpAcas1virulence on detached rubber tree leaves. 
Detached leaves of the susceptible (IRCA631 and PB217) and tolerant (GT1) rubber clones were inoculated with $\mathrm{CCP}$ or $c c p \Delta c a s 1$ conidial suspension at 50 conidia/ $\mu 1$. For each clone, four leaves were treated with 6 drops of conidial suspension each. At four or seven days post inoculation (dpi), surface of necrotic tissue $\left(\mathrm{mm}^{2}\right)$ was measured around each drop. Data are means of at least four biological replicates. Water-treated controls did not induce any symptoms (Supplementary Table S1). Letters indicate the significance of the between-group differences (Kruskal-Wallis test, $\alpha=0.05)$

Figure 7 - Effect of leaf abrasion on CCP and ccp $\triangle$ cas 1 virulence on detached rubber tree leaves.

Detached leaves of susceptible (IRCA631 and PB217) and tolerant (GT1) rubber clones were inoculated with CCP or ccp $\triangle$ cas 1 conidial suspension at 5 conidia/ $\mu 1$, with (right) or without (left) gentle abrasion of the lower epidermis. For each condition, four leaves were treated with 6 drops of conidia suspension each. After four days, the surface of necrotic tissue $\left(\mathrm{mm}^{2}\right)$ was measured around each drop. Data are means of at least four biological replicates. Water-treated controls did not induce any symptoms (Supplementary Table S1). Letters indicate the significance of betweengroup differences (Kruskal-Wallis test, $\alpha=0.05$ ).

Figure 8 - Virulence of CCP and ccp 4 cas 1 on non-detached rubber tree leaves.

Leaves of four rubber clones (IRCA631, GT1, PB260 and RRIM600) were inoculated with wildtype (CCP) and mutant (ccp $\Delta$ cas 1$)$ strains while still attached to the tree. For each clone, three leaves were treated with 6 drops of conidia suspension each at 10 conidia/ $\mu$ l from either CCP or ccp 4 cas 1 . For each strain/clone combination, pictures of leaf symptoms were taken 9 days after inoculation. Pathogenicity was scored by analyzing the extent of symptoms as the mean surface of necrotic tissue $\left(\mathrm{mm}^{2}\right)$ for 4 biological replicates. Water-treated controls did not induce any symptoms (Supplementary Table S1). Data were analyzed using Welch's ANOVA. Letters indicate the significance of between-group differences (Kruskal-Wallis test, $\alpha=0.05$ ). 
Figure 9 - Quantification of CCP and ccpAcas 1 fungal mass by qPCR in rubber tree leaves inoculated with or without cassiicolin supplementation.

Detached leaves of the susceptible IRCA631 rubber clone were inoculated on the abaxial face, after gentle abrasion of the lower epidermis, with $20 \mu \mathrm{l}$ of conidial suspension from CCP or ccp $\triangle$ cas 1 ( 5 conidia/ $\mu \mathrm{l}$ ), supplemented or not with $10 \mu \mathrm{l}$ of purified cassiicolin at $5 \mathrm{ng} / \mu \mathrm{l}$ (Tox5). Controls were abraded water-treated leaves, with or without toxin. After four days in the dark at $26^{\circ} \mathrm{C}$, three leaf disks $\left(2.2 \mathrm{~cm}^{2}\right)$ per leaflet were sampled at the inoculation points. Representative symptoms are shown for each condition. The amount of fungal genomic DNA (ng) was determined by the standard curve method using C. cassiicola Cc-Btub-F1/Cc-Btub-R1 primers (Table 2). Bars indicate standard errors of the mean between four biological replicates. Letters indicate the significance of between-group differences (Kruskal-Wallis test, $\alpha=0.05$ ).

Figure 10 - Toxicity of 24 treatments ( $\mathrm{Tr}$ ) on 18 clones (Cl) expressed as percentage of induced electrolyte leakage (EL\%).

Treatments are culture filtrates from C. cassiicola strains of various types (including CCP and ccp $\Delta$ cas 1 , in bold), purified cassiicolin at different concentrations $(1,5$ and $10 \mathrm{ng} / \mu 1$ for Tox 1 , Tox 5 and Tox10, respectively), and blank treatments (water for Tox0 and culture medium for $\mathrm{Cz}$ ). Colors represent the gradient of the electrolyte leakage percentages (EL\%), from lowest (green) to highest (red). Means per clone and per treatment are at the edges. Hierarchical classification of clones and treatments was based on Euclidean distances and used Ward's method of clustering, on R software. Significance of the clone and treatment clusters was estimated using the SNK test (risk $\alpha=0.05$ ).

Supplementary Figure - Toxicity of the purified cassiicolin Cas1 on a susceptible clone, with or without previous abrasion of the leaves.

Detached leaves of the susceptible rubber clone PB260 were treated with purified cassiicolin at 5 $\mathrm{ng} / \mu \mathrm{l}$ (Tox5) or sterile water (control). The treatments ( 2 drops of $10 \mu \mathrm{l}$ per leaflet) were applied on the abaxial face of the leaf, with (dark grey) or without (light grey) local abrasion of the epidermis. 
Phytotoxicity was assessed two days after treatment, by conductivity measurement of the induced electrolyte leakage $(\mathrm{C} 1$, in $\mu \mathrm{S} / \mathrm{cm})$. For each condition, three biological repeats were performed. Letters indicate the significance of between-group differences (Kruskal-Wallis test, $\alpha=0.05$ ).

\section{References}

Akamatsu, H., et al., 1997. AAL-toxin-deficient mutants of Alternaria alternata tomato pathotype by restriction enzyme-mediated integration. Phytopathology. 87, 967-972.

Bari, R., Jones, J. D. G., 2009. Role of plant hormones in plant defence responses. Plant Molecular Biology. 69, 473-488.

Barthe, P., et al., 2007. Structural analysis of cassiicolin, a host-selective protein toxin from Corynespora cassiicola. J. Mol. Biol. 367, 89-101.

Biswal, B., et al., 1983. Senescence of detached fern leaves. Plant and Cell Physiology. 24, 12031208.

Breton, F., et al., 2000. Role of cassiicolin, a host-selective toxin, in pathogenicity of Corynespora cassiicola, causal agent of a leaf fall disease of Hevea. J. Rubber Res. 3, 115-128.

Chang, S., et al., 1993. A simple and efficient method for isolating RNA from pine trees. Plant Molecular Biology Reporter. 11, 113-116.

Chanruang, N., Status of Corynespora leaf fall in Thailand. IRRDB Workshop on Corynespora Leaf Fall of Rubber, 6-14 June, (Kuala Lumpur, Malaysia and Medan, Indonesia), 2000.

de Lamotte, F., et al., 2007. Purification and characterization of cassiicolin, the toxin produced by Corynespora cassiicola, causal agent of the leaf fall disease of rubber tree. J Chromatogr. B. Analyt. Technol. Biomed. Life Sci. 849, 357-62.

De Wit, P. J., et al., 2016. Fungal plant pathogenesis mediated by effectors. Microbiol Spectr. 4. 
Déon, M., et al., 2012a. Characterization of a cassiicolin-encoding gene from Corynespora cassiicola, pathogen of rubber tree (Hevea brasiliensis). Plant Science. 185-186, 227-237.

Déon, M., et al., 2014. Diversity of the cassiicolin gene in Corynespora cassiicola and relation with the pathogenicity in Hevea brasiliensis. Fungal Biology. 118, 32-47.

Déon, M., et al., 2012b. First characterization of endophytic Corynespora cassiicola isolates with variant cassiicolin genes recovered from rubber trees in Brazil. Fungal Diversity. 54, 87-99.

Dixon, L. J., et al., 2009. Host specialization and phylogenetic diversity of Corynespora cassiicola. Phytopathology. 99, 1015-27.

Dung, P. T., Hoan, N. T., 2000. Corynespora leaf fall on rubber in Vietnam, a new record. Proceeding of IRRDB Symposium. 273-275.

Guillemette, T., et al., 2011. Methods for investigating the UPR in filamentous fungi. Methods Enzymol. 490, 1-29.

Hallé, F., Martin, R., 1968. Etude de la croissance rythmique chez l'hévéa (Hevea brasiliensis) Müll. Arg., (Euphorbiacées, crotonoïdées). Adansonia. 8, 475-503.

Heil, M., Land, W. G., 2014. Danger signals - damaged-self recognition across the tree of life. Frontiers in Plant Science. 5, 578.

Huang, H.-K., et al., 2010. Subcutaneous infection caused by Corynespora cassiicola, a plant pathogen. Journal of Infection. 60, 188-190.

Jinji, P., et al., 2007. First record of Corynespora leaf fall disease of Hevea rubber tree in China. Australasian Plant Disease Notes. 2, 35-36.

Kar, M., et al., 1993. Sensitivity to photodamage increases during senescence in excised leaves. Journal of Plant Physiology. 141, 538-544.

Liu, X., et al., 2017. CCK1, a PMK1-type MAP kinase is required for hyphal growth, pigmentation, conidiation, enzyme activity, osmotic stress response, and pathogenicity in Corynespora cassiicola. European Journal of Plant Pathology. 
Liu, Z., et al., 2009. SnTox3 acts in effector triggered susceptibility to induce disease on wheat carrying the Snn3 gene. PLoS Pathog. 5, e1000581.

Liu, Z., et al., 2015. Necrotrophic effector-triggered susceptibility (NETS) underlies the barleyPyrenophora teres $f$. teres interaction specific to chromosome 6H. Mol Plant Pathol. 16, 188-200.

Liu, Z., et al., 2012. The cysteine rich necrotrophic effector SnTox1 produced by Stagonospora nodorum triggers susceptibility of wheat lines harboring Snn1. PLoS Pathog. 8, e1002467.

Liyanage, A. D. S., et al., 1986. Corynespora leaf spot disease of rubber (Hevea brasiliensis) - a new record. J Rubber Res Inst Sri Lanka. 65, 47-50.

Lopez, D., et al., 2012. Insights into Populus XIP aquaporins: evolutionary expansion, protein functionality, and environmental regulation. J Exp Bot. 63, 2217-30.

Lopez, D., et al., 2018. Genome-wide analysis of Corynespora cassiicola leaf fall disease putative effectors. Front Microbiol. 9, 276.

Lu, S., et al., 2014. A dimeric PR-1-type pathogenesis-related protein interacts with ToxA and potentially mediates ToxA-induced necrosis in sensitive wheat. Mol Plant Pathol. 15, 65063.

Manju, M., et al., 2001. Incidence and severity of Corynespora Leaf Fall (CLF) disease of rubber in coastal Karnataka and north Malabar region of Kerala. Indian Journal of Natural Rubber Research. 14, 137-141.

Manju, M. J., et al., 2015. Major diseases of Hevea brasiliensis in rubber growing regions of South India. Environment \& Ecology. 33, 1299-1302.

Manning, V. A., Ciuffetti, L. M., 2015. Necrotrophic effector epistasis in the Pyrenophora triticirepentis-wheat interaction. PLoS One. 10, e0123548.

Mengiste, T., 2012. Plant immunity to necrotrophs. Annu. Rev. Phytopathol. 50, 267-94. 
Oliver, R., et al., 2014. Absence of detectable yield penalty associated with insensitivity to Pleosporales necrotrophic effectors in wheat grown in the West Australian wheat belt. Plant Pathology. 63, 1027-1032.

Pandey, D., et al., 2016. Plant defense signaling and responses against necrotrophic fungal pathogens. Journal of Plant Growth Regulation. 35, 1159-1174.

Pfaffl, M. W., et al., 2004. Determination of stable housekeeping genes, differentially regulated target genes and sample integrity: BestKeeper - Excel-based tool using pair-wise correlations. Biotechnology Letters. 26, 509-515.

Promputtha, I., et al., 2007. A phylogenetic evaluation of whether endophytes become saprotrophs at host senescence. Microb Ecol. 53, 579-90.

Pujade-Renaud, V., et al., Corynespora cassiicola CCP v1.0, genome sequence. JGI, 1000 fungal genomes project. DOE-JGI, 2014.

Rajalakshmi, V. K., Kothandaraman, R., Current status of Corynespora leaf fall in India. The occurrence and management. Proceedings of Workshop on Corynespora Leaf Fall Disease of Hevea Rubber, 1996, pp. 37-43.

Risterucci, A. M., et al., 2000. A high-density linkage map of Theobroma cacao L. TAG Theoretical and Applied Genetics. 101, 948-955.

Sinulingga, W. S., Soepena, F. H., Current status of Corynespora leaf fall in Indonesia. Workshop on Corynespora Leaf Fall Disease of Hevea Rubber Medan, Indonesia, 1996, pp. 29-36.

Suryanarayanan, T. S., 2017. Fungal endophytes: an eclectic review. Kavaka. 48, 1-9.

Sweigard, J. A., et al., 1995. Identification, cloning, and characterization of PWL2, a gene for host species specificity in the rice blast fungus. Plant Cell. 7, 1221-33.

Tan, A. M., et al., 1992. Survey of major leaf diseases of rubber in peninsular Malaysia. Planters' Bulletin - Rubber Research Institute of Malaysia. 51-62.

Tan, K.-C., et al., 2010. Proteinaceous necrotrophic effectors in fungal virulence. Functional Plant Biology. 37, 907-912. 
Thimann, K. V., Satler, S., 1979. Relation between senescence and stomatal opening: Senescence in darkness. Proc Natl Acad Sci U S A. 76, 2770-2773.

Tran, D. M., et al., 2016. Genetic determinism of sensitivity to Corynespora cassiicola exudates in rubber tree (Hevea brasiliensis). PLoS One. 11, e0162807.

U'Ren, J. M., Arnold, A. E., 2016. Diversity, taxonomic composition, and functional aspects of fungal communities in living, senesced, and fallen leaves at five sites across North America. PeerJ. 4, e2768.

Van Ooijen, J. W., MapQTL 6, Software for the mapping of quantitative trait loci in experimental populations of diploid species Kyazma, B V, Wageningen, Netherlands, 2009.

Vleeshouwers, V. G. A. A., Oliver, R. P., 2014. Effectors as Tools in Disease Resistance Breeding Against Biotrophic, Hemibiotrophic, and Necrotrophic Plant Pathogens. Molecular PlantMicrobe Interactions. 27, 196-206.

Yamada, H., et al., 2013. Rare case of fungal keratitis caused by Corynespora cassiicola. Journal of infection and chemotherapy : official journal of the Japan Society of Chemotherapy. 19, 1167-9.

Yan, X. X., et al., 2016. CARD9 mutation linked to Corynespora cassiicola infection in a Chinese patient. Br J Dermatol. 174, 176-9.

Yu, J.-H., et al., 2004. Double-joint PCR: a PCR-based molecular tool for gene manipulations in filamentous fungi. Fungal Genetics and Biology. 41, 973-981.

Zipfel, C., 2014. Plant pattern-recognition receptors. Trends Immunol. 35, 345-51. 
A

\begin{tabular}{l}
\hline P1) \\
\hline $5^{\prime} \operatorname{Cas} 1(470 \mathrm{bp})$ \\
\hline P2
\end{tabular}

M13F

P2

hph gene (1660 bp)

$\square$ P3

3' Cas1 (505 bp)

P4

B

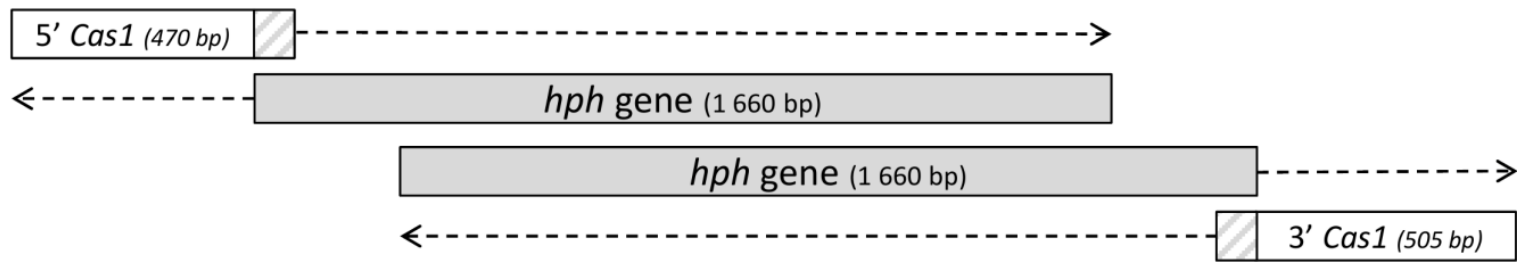

C

\begin{tabular}{|c|c|c|}
\hline 5' Cas1 (444 bp) & hph gene (1 $660 \mathrm{bp})$ & \\
\hline & hph gene (1 $660 \mathrm{bp})$ & $3^{\prime}$ Cas1 (488 bp) \\
\hline
\end{tabular}

D

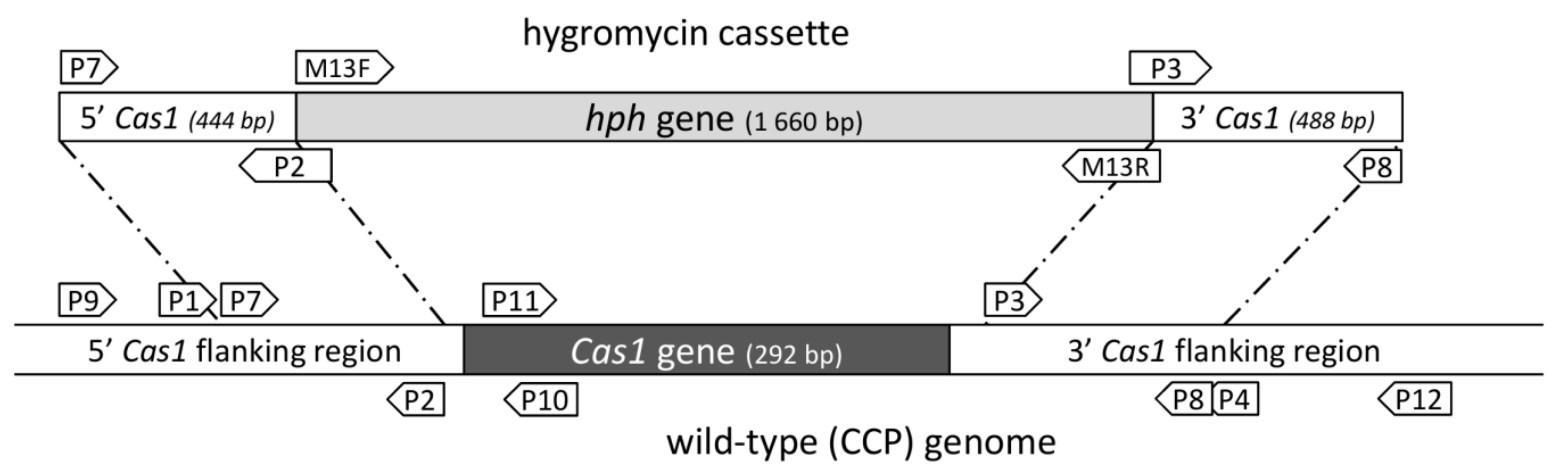




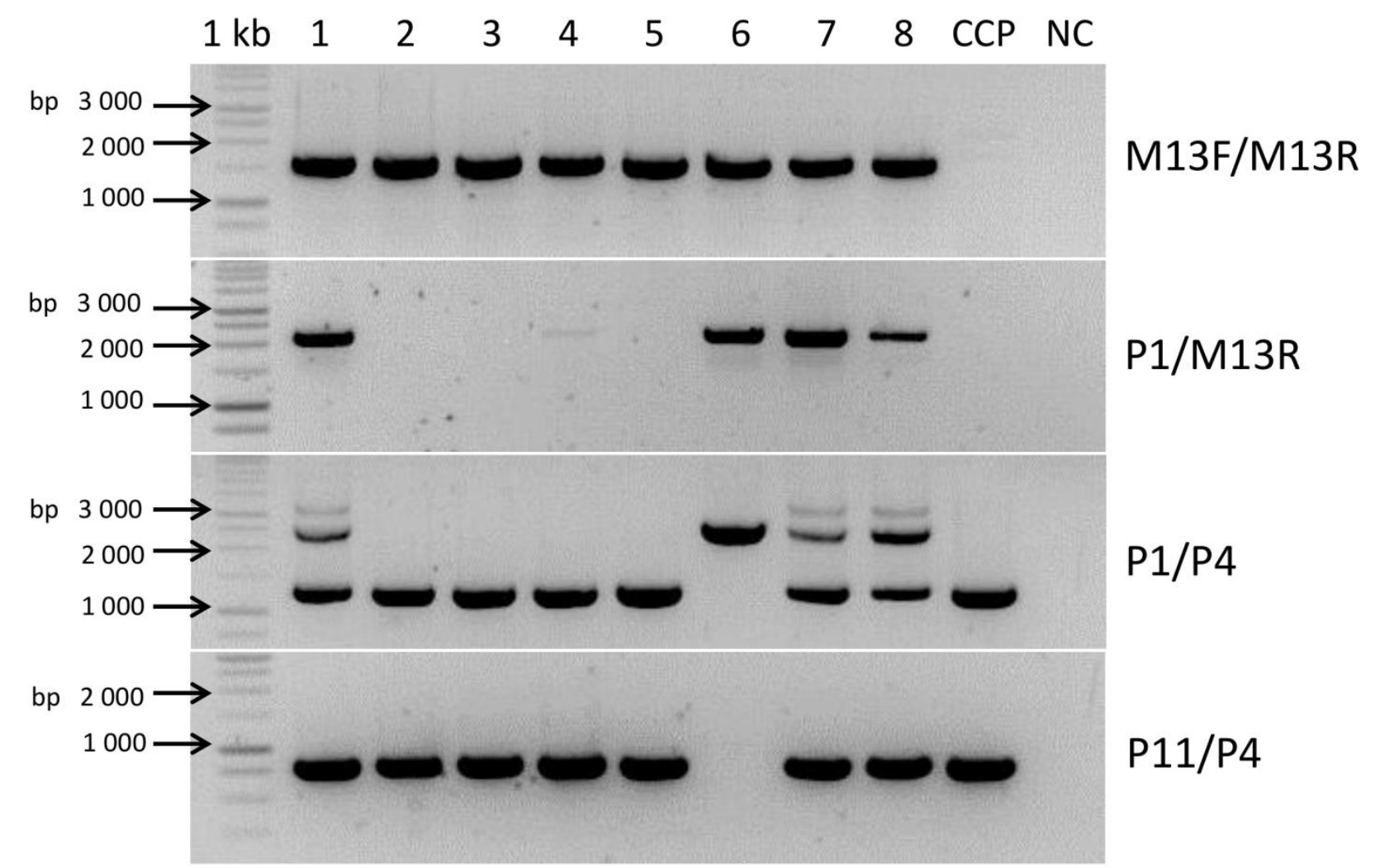

A

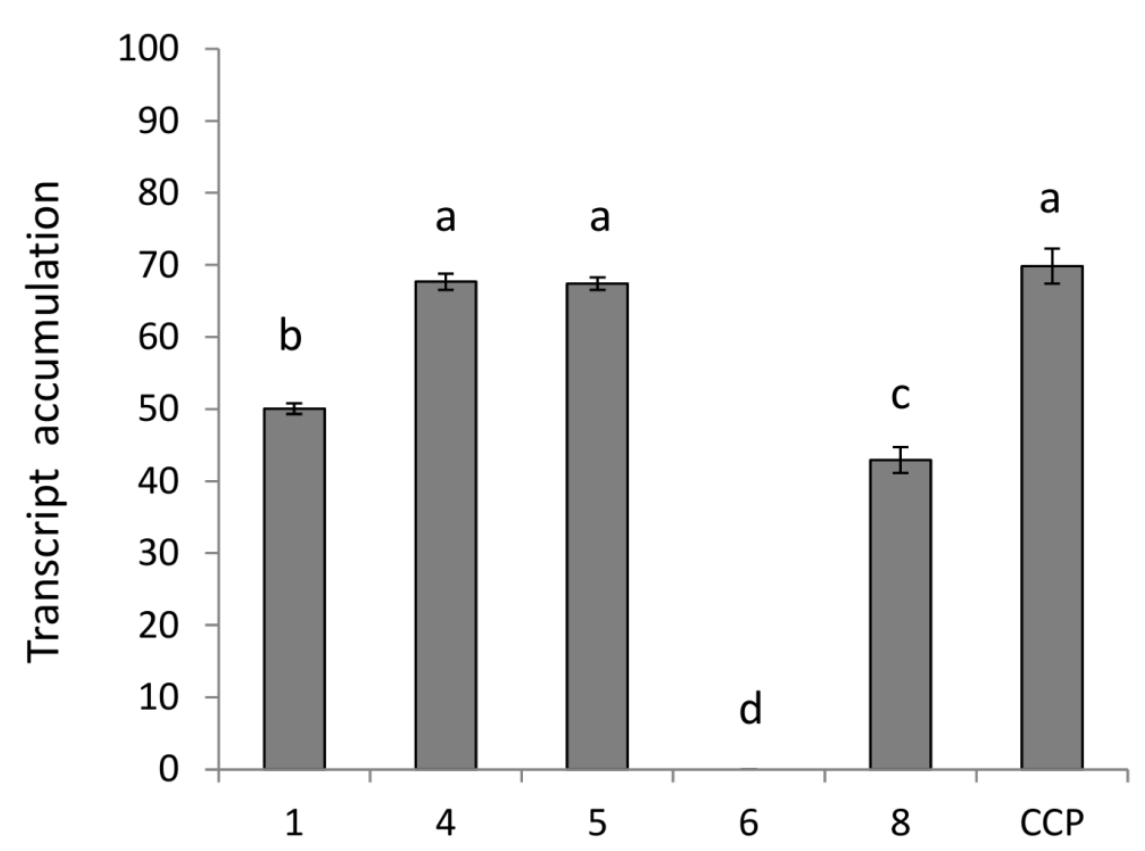

B

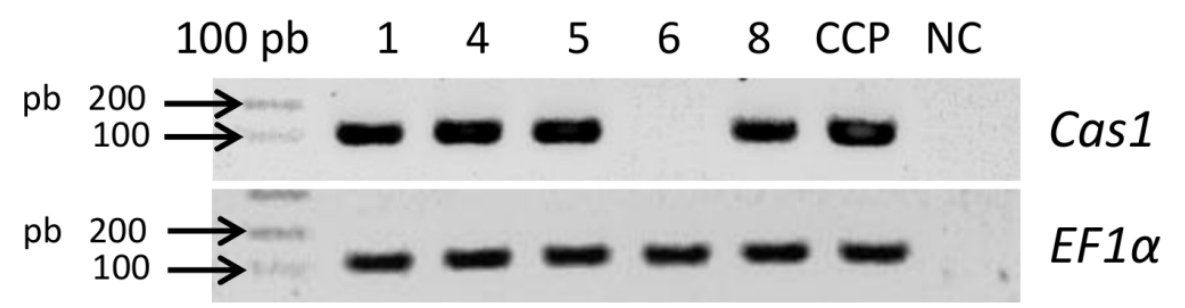


A

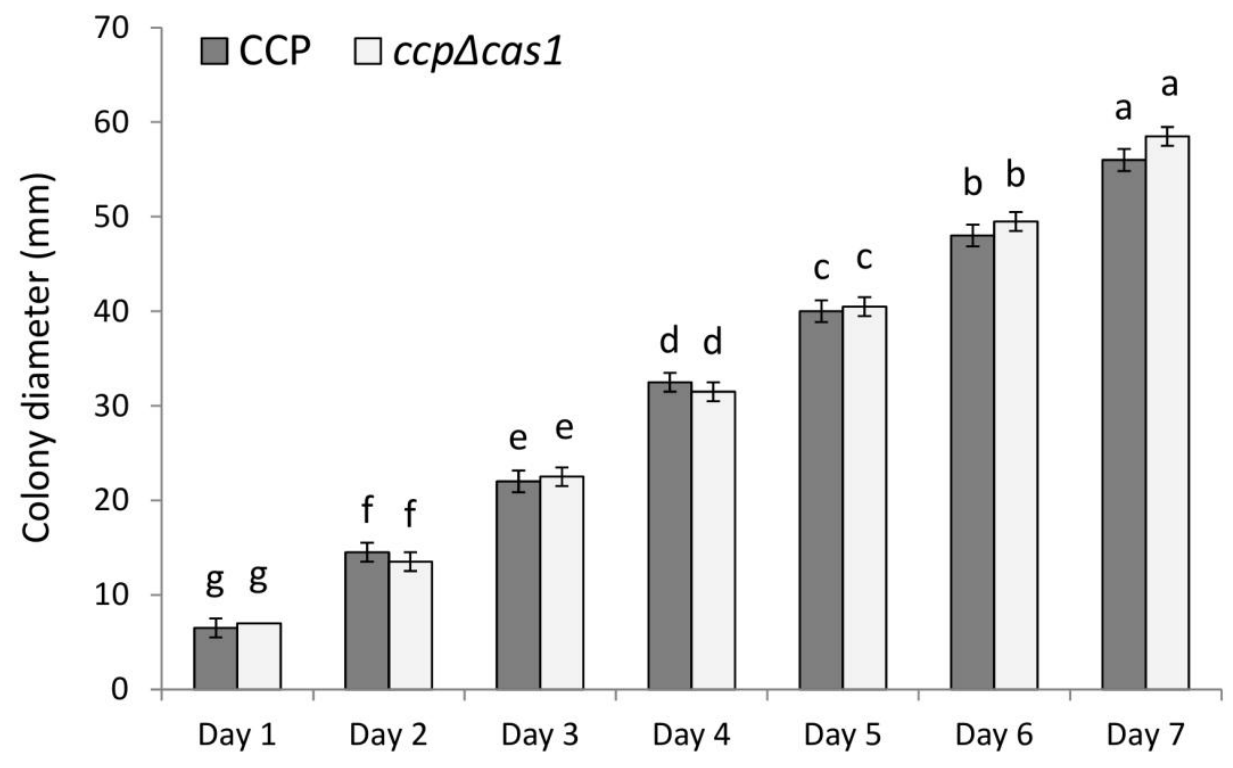

B

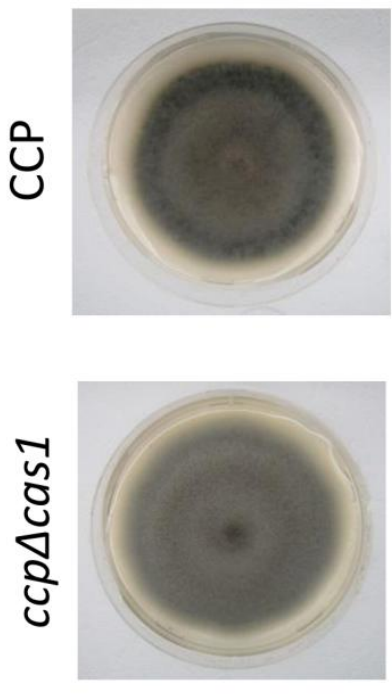

$$
\text { 10 }
$$

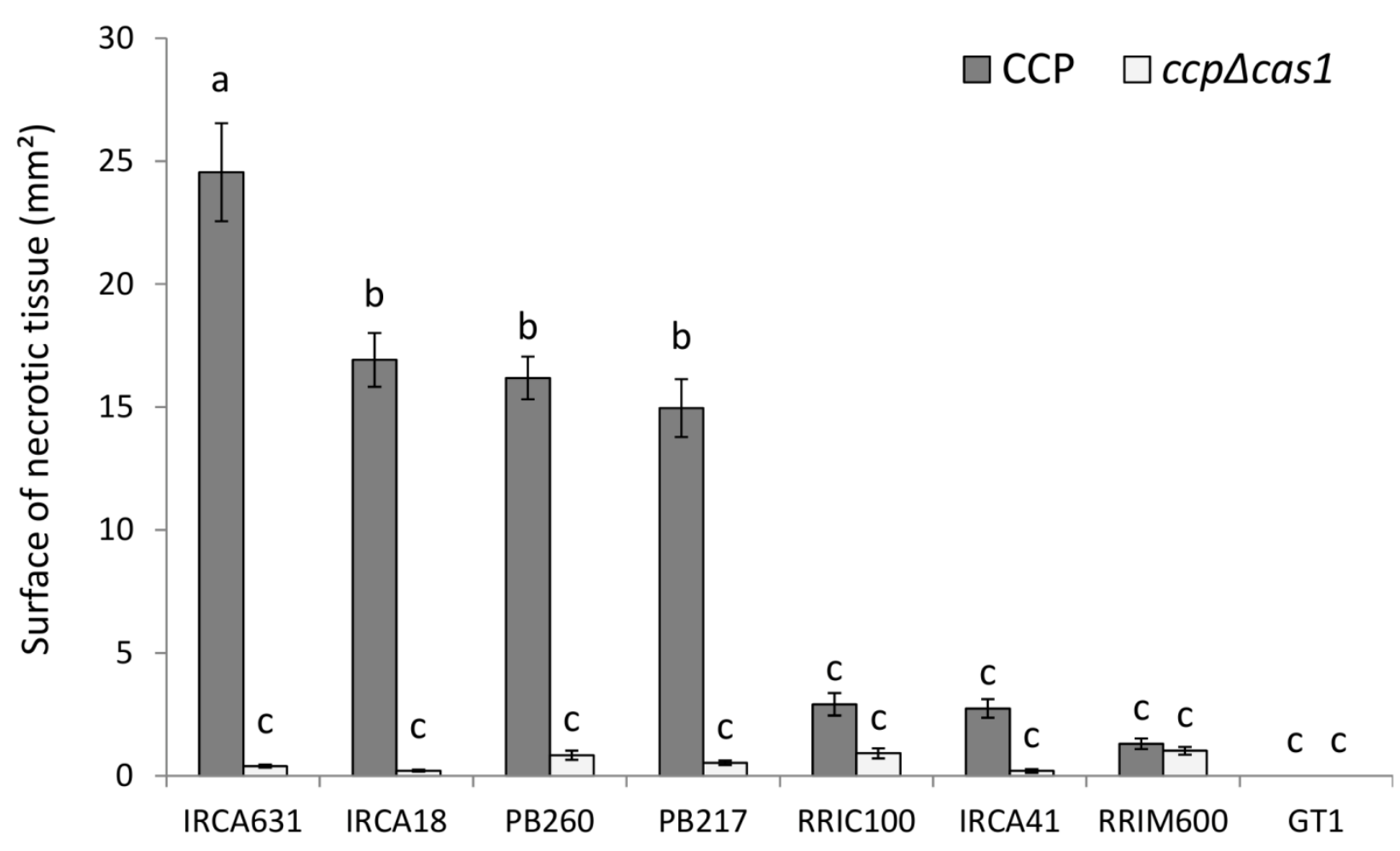



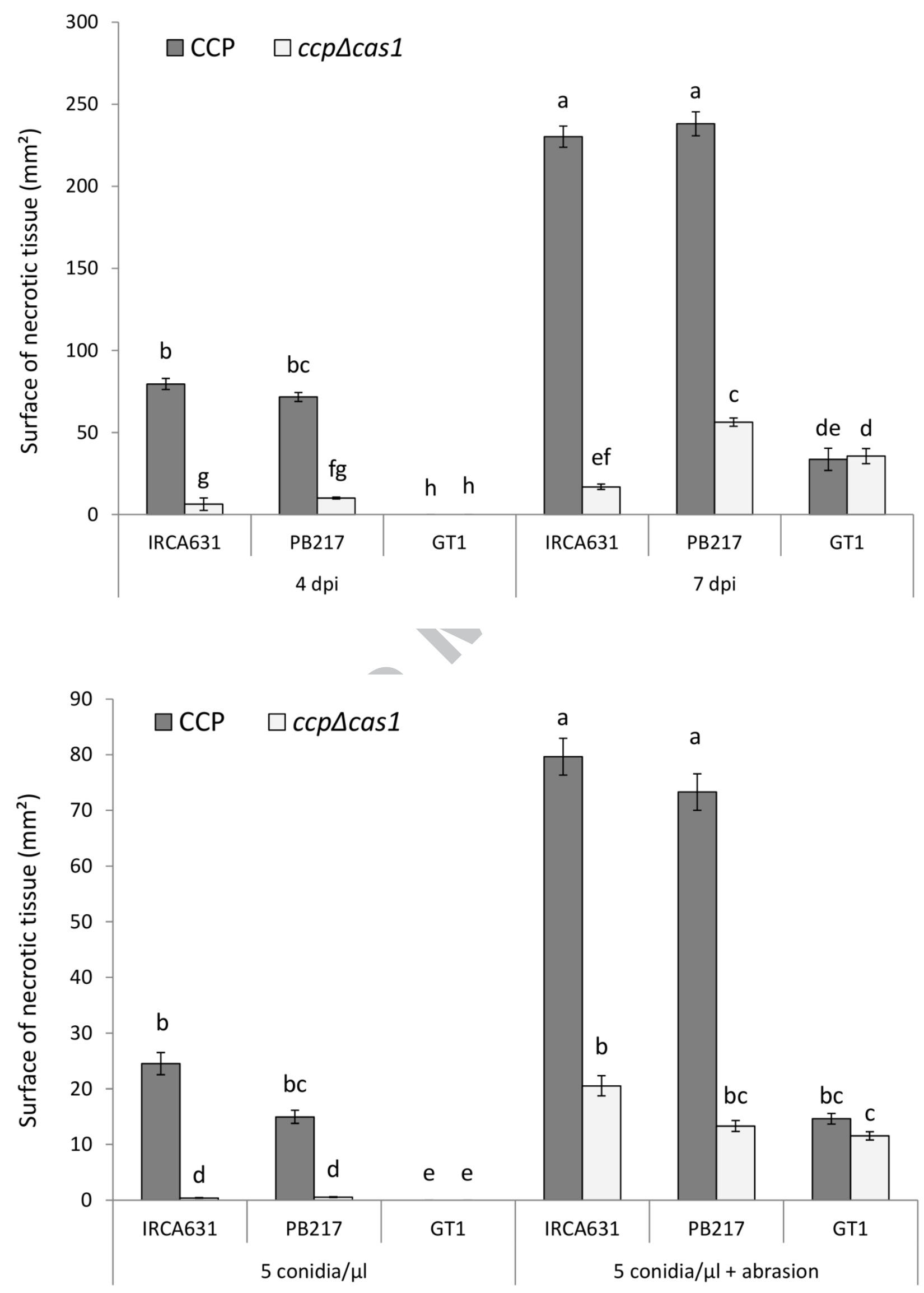

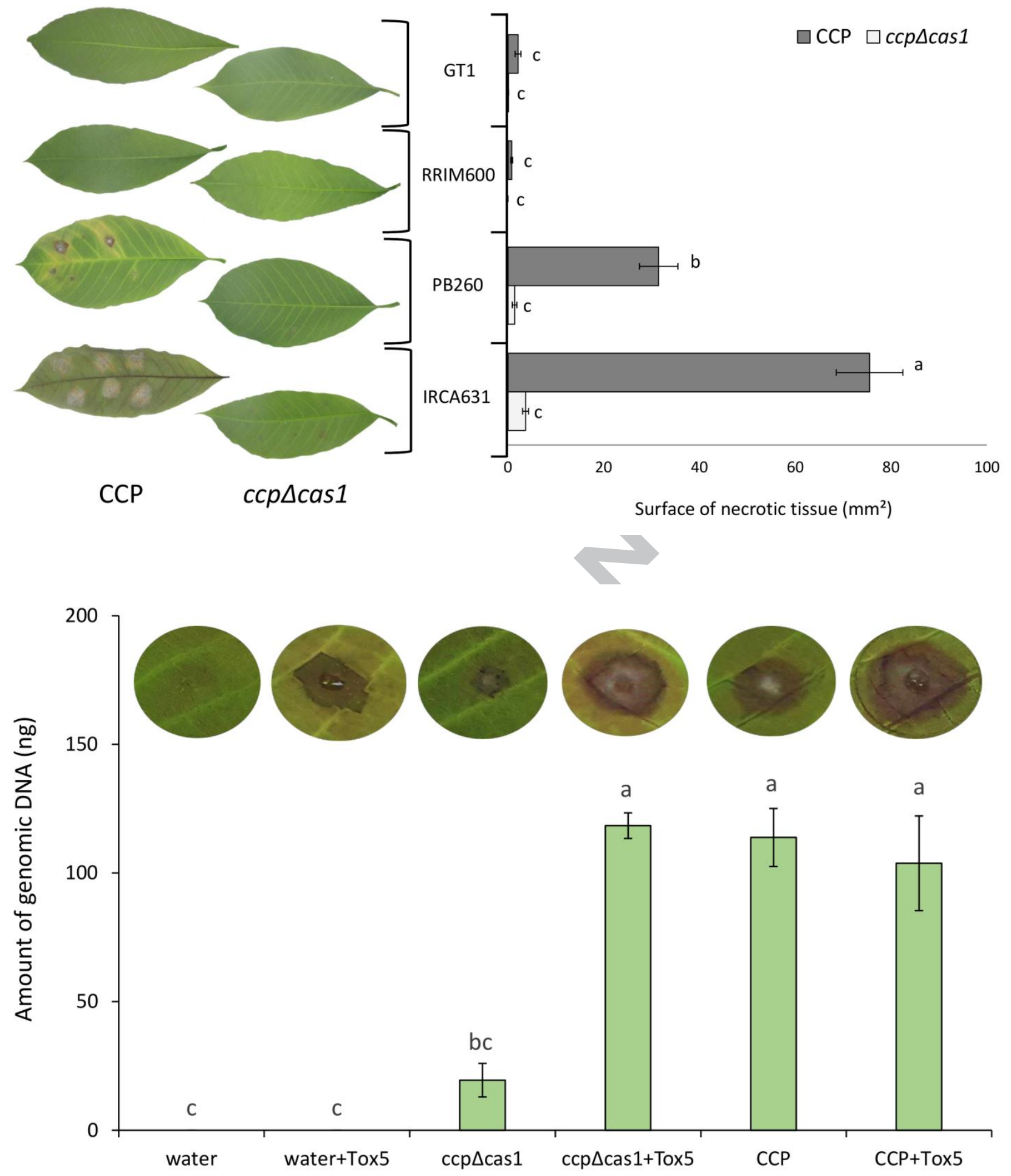

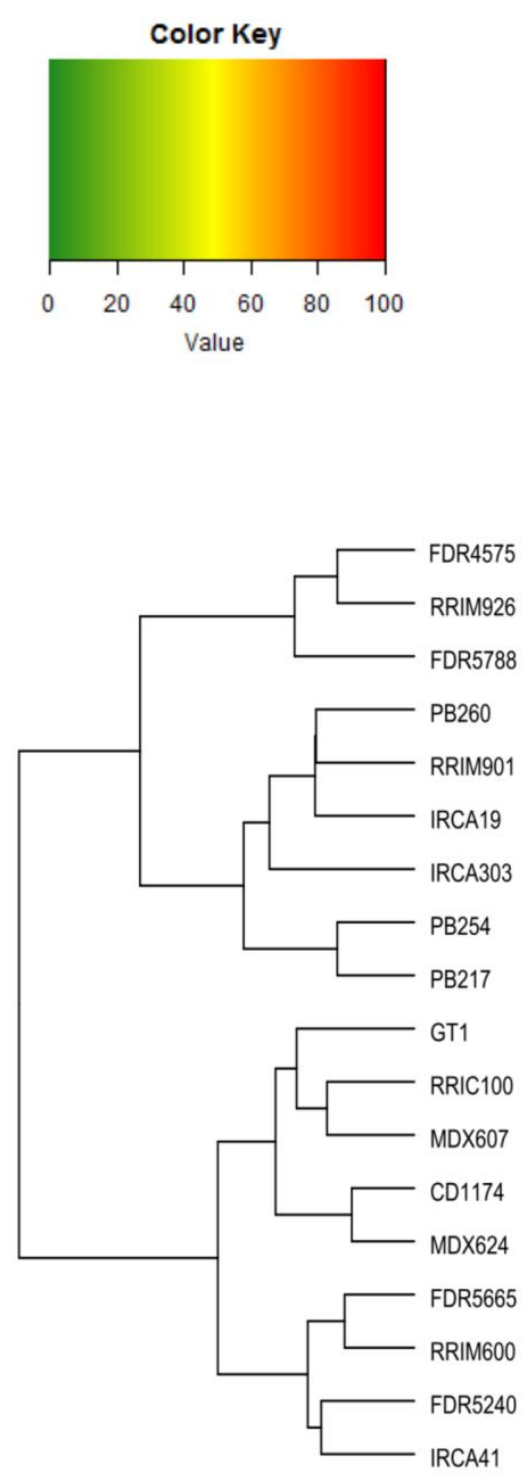

Mean/treatment

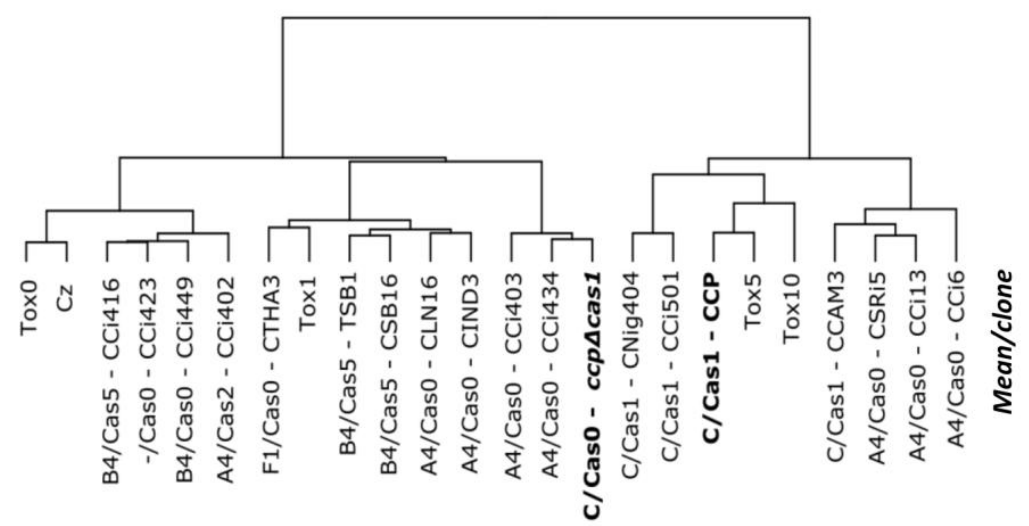

$\operatorname{Tr} 6$

$\operatorname{Tr} 5$

\begin{tabular}{l|l|l|l|l} 
Tr4 & Tr3 & Tr2 & Tr1
\end{tabular}

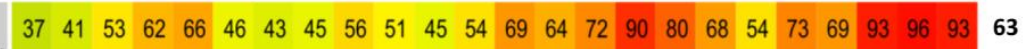

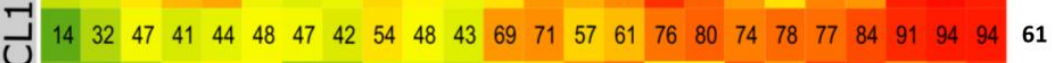
$\begin{array}{llllllllllllllllllllllllllll}18 & 24 & 34 & 45 & 51 & 48 & 28 & 29 & 43 & 44 & 39 & 42 & 56 & 71 & 79 & 44 & 51 & 82 & 70 & 87 & 86 & 70 & 78 & 90 & \mathbf{5 5}\end{array}$

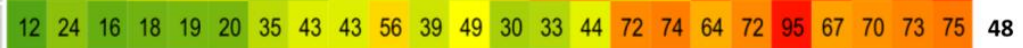
$\begin{array}{lllllllllllllllllllllllll}17 & 23 & 30 & 33 & 35 & 30 & 25 & 22 & 26 & 24 & 35 & 31 & 44 & 52 & 49 & 64 & 66 & 53 & 51 & 72 & 58 & 79 & 77 & 81 & 45\end{array}$ $\begin{array}{llllllllllllllllllllllllll}\text { N } & 15 & 19 & 24 & 21 & 24 & 29 & 18 & 53 & 23 & 34 & 29 & 35 & 64 & 58 & 53 & 84 & 75 & 65 & 72 & 89 & 54 & 50 & 51 & 63 & 46\end{array}$ $\begin{array}{lllllllllllllllllllllllllll}\cup & 29 & 28 & 18 & 20 & 16 & 23 & 64 & 44 & 50 & 51 & 29 & 40 & 30 & 47 & 34 & 75 & 89 & 43 & 33 & 46 & 42 & 47 & 45 & 74 & 43\end{array}$ $\begin{array}{lllllllllllllllllllllllll}22 & 22 & 29 & 23 & 21 & 18 & 38 & 55 & 44 & 61 & 33 & 47 & 16 & 23 & 22 & 42 & 45 & 84 & 87 & 88 & 51 & 45 & 57 & 57 & 43\end{array}$ $\begin{array}{lllllllllllllllllllllllll}19 & 18 & 15 & 23 & 17 & 13 & 45 & 45 & 47 & 41 & 41 & 43 & 16 & 15 & 23 & 57 & 48 & 63 & 59 & 76 & 44 & 41 & 42 & 42 & 37\end{array}$ $\begin{array}{lllllllllllllllllllllllll}31 & 38 & 42 & 51 & 32 & 39 & 36 & 25 & 33 & 39 & 30 & 38 & 43 & 48 & 47 & 38 & 46 & 35 & 39 & 39 & 40 & 39 & 41 & 37 & 39\end{array}$ $\begin{array}{lllllllllllllllllllllllll}19 & 18 & 24 & 19 & 24 & 39 & 27 & 25 & 31 & 48 & 37 & 39 & 35 & 49 & 48 & 42 & 58 & 36 & 54 & 83 & 55 & 60 & 49 & 44 & 40\end{array}$ $\begin{array}{lllllllllllllllllllllllll}24 & 22 & 16 & 25 & 22 & 23 & 45 & 37 & 21 & 34 & 38 & 37 & 25 & 25 & 32 & 25 & 41 & 42 & 46 & 79 & 43 & 62 & 42 & 75 & 37\end{array}$ $\begin{array}{llllllllllllllllllllllllll}24 & 28 & 24 & 19 & 20 & 30 & 22 & 17 & 27 & 35 & 29 & 36 & 41 & 37 & 52 & 32 & 25 & 43 & 22 & 41 & 55 & 73 & 78 & 78 & 37\end{array}$ $\begin{array}{llllllllllllllllllllllllll} & 21 & 18 & 14 & 23 & 14 & 16 & 21 & 16 & 26 & 23 & 28 & 41 & 45 & 33 & 47 & 47 & 32 & 31 & 38 & 44 & 55 & 55 & 62 & 87 & 35\end{array}$

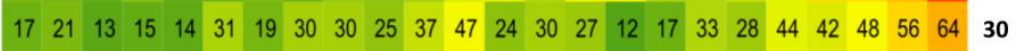
$\begin{array}{lllllllllllllllllllllllll}21 & 15 & 14 & 24 & 18 & 14 & 22 & 20 & 29 & 34 & 29 & 35 & 13 & 23 & 23 & 19 & 31 & 30 & 29 & 29 & 41 & 42 & 42 & 36 & \mathbf{2 6}\end{array}$ $\begin{array}{llllllllllllllllllllllllll}12 & 18 & 26 & 26 & 37 & 33 & 20 & 18 & 25 & 17 & 19 & 18 & 31 & 31 & 32 & 31 & 36 & 19 & 30 & 25 & 21 & 23 & 22 & 37 & \mathbf{2 5}\end{array}$ $\begin{array}{llllllllllllllllllllllllllll}13 & 11 & 14 & 15 & 12 & 12 & 22 & 20 & 17 & 22 & 26 & 29 & 14 & 14 & 14 & 23 & 15 & 24 & 35 & 43 & 39 & 13 & 35 & 15 & \mathbf{2 1}\end{array}$

$\begin{array}{llllllllllllllllllllllll}20 & 23 & 25 & 28 & 27 & 29 & 32 & 33 & 35 & 38 & 34 & 40 & 37 & 39 & 42 & 48 & 50 & 50 & 50 & 63 & 53 & 56 & 58 & 63\end{array}$ 


\section{Highlights}

- Cassiicolin is a key necrotrophic effector in the CLF disease of rubber tree

- The cassiicolin-deleted mutant ccp $\Delta$ cas 1 is avirulent on intact rubber tree leaves

- ccp $\Delta$ cas 1 shows moderate residual virulence on detached and wounded leaves

- QTL associated with the sensitivity to Cas1 are no longer detected with ccp $\triangle$ cas 1 